\title{
The role of carbon grains in the deuteration of $\mathrm{H}_{2}$
}

\author{
S. Cazaux ${ }^{1}$, P. Caselli ${ }^{2}$, V. Cobut ${ }^{3}$, and J. Le Bourlot ${ }^{4}$ \\ 1 Kapteyn Astronomical Institute, PO box 800, 9700AV Groningen, The Netherlands \\ e-mail: [cazaux; S.M.Cazaux] @astro.rug.nl \\ 2 School of Physics and Astronomy, University of Leeds, LS2 9JT, Leeds, UK \\ ${ }^{3}$ Laboratoire pour l'Étude du Rayonnement et de la Matière, UMR 8112 du CNRS, Observatoire de Paris et Université de \\ Cergy-Pontoise, 5 mail Gay-Lussac, 95031 Cergy-Pontoise Cedex, France \\ 4 LUTH, UMR 8102 CNRS, Universite Paris 7 and Observatoire de Paris, Place J. Janssen, 92195 Meudon, France
}

Received 4 September 2007 / Accepted 19 February 2008

\begin{abstract}
Aims. The production of molecular hydrogen and its deuterated forms onto carbonaceous dust grains is investigated in detail. The goal of this study is to estimate the importance of the chemistry occuring on grain surfaces for the deuteration of $\mathrm{H}_{2}$. Furthermore, we aim to find a robust and general surface chemical model that can be used in different astrophysical environments.

Methods. Surface processes are described for the cases of graphitic and amorphous-carbon grains, where laboratory work is available. Langmuir-Hinshelwood, as well as Eley-Rideal surface chemistries are included in the model and their relative contributions highlighted. Analytic expressions are derived for $\mathrm{H}_{2}, \mathrm{HD}$, and $\mathrm{D}_{2}$ formation efficiencies for both types of grains. Rate equations are tested against stochastic methods.

Results. As expected, rate equations and stochastic methods diverge for grain sizes below a critical value $a_{\text {crit }}$. For these sizes, $\mathrm{D}_{2}$ formation decreases to favour HD formation. The formation efficiencies of $\mathrm{H}_{2}$ and $\mathrm{D}_{2}$ can be calculated by adding a correction factor to the rate equations methods (this factor is a simple exponential factor that becomes unity when $a>a_{\text {crit }}$ ). We find that, because of the presence of chemisorbed sites, which can store atoms to form molecules up to high grain temperatures, the formation efficiency of $\mathrm{HD}$ and $\mathrm{D}_{2}$ is very high compared to models where only physisorption sites are taken into account. When considering a realistic distribution of dust grains, we find that the formation rates of $\mathrm{H}_{2}$ and $\mathrm{HD}$ are enhanced by an order of magnitude if small grains are taken into account. The formation of $\mathrm{D}_{2}$, on the other hand, comes from the contribution of small $(\leq 100 \AA)$ and big $(\geq 100 \AA)$ grains, depending on the $\mathrm{D} / \mathrm{H}$ ratio, the grain temperature, and the volume density. The processes described in this paper, which allow a strong enhancement of the deuterated forms of molecular hydrogen, could explain the high degree of deuterium fractionation observed in protostellar environments.
\end{abstract}

Key words. ISM: dust, extinction - ISM: molecules

\section{Introduction}

Formation of molecular hydrogen has been studied for decades but is still the subject of polemics. Because of its importance for establishing the time scale of molecular cloud formation (e.g. Bergin et al. 2004) as a coolant in low metallicity environments (Tegmark et al. 1997) or as the primary ingredient for astrochemistry, the formation of $\mathrm{H}_{2}$ occurring through grain surface reactions (Gould \& Salpeter 1963), is the most studied surface reaction. However, there are considerable uncertainties associated with this simple reaction caused mainly by our ignorance of dust grain constitution; see the review by Hollenbach \& Tielens (1999), where one also finds references to much of the earlier work. Because of this, recent investigations have focused on the structure of dust grains, the interaction between grain surfaces and accreting atoms, as well as on the theoretical approach to treating surface chemistry and to coupling it with gas-phase chemistry (Chang et al. 2007). Interaction between $\mathrm{H}$ atoms and dust grains has been extensively studied both theoretically (Sha \& Jackson 2004, 2002; Jeloaica \& Sidis 1999; Parneix \& Brechignac 1998; Klose 1992) and experimentally (Pirronello et al. 1997a,b, 1999; Dulieu et al. 2005; Zecho et al. 2002; Hoenekaer et al. 2003), allowing better understanding of the morphology of dust grains.
The past discussion and also much recent work have centred on how, for the case (Langmuir Hinshelwood mechanism) where the two $\mathrm{H}$ atoms are physisorbed (attached to the surface by Van der Waals forces), one predicts efficient $\mathrm{H}_{2}$ formation in a very narrow temperature range. This specificity is backed up by laboratory studies (Pironnello 1997a,b, 1999). Although the predicted temperature range for significant formation of $\mathrm{H}_{2}$ is close to the observed interstellar grain temperatures (Boulanger et al. 1996; Dwek et al. 1997; Rawlings et al. 2005) of around $15-18 \mathrm{~K}$, it seems unlikely that this coincidence is found everywhere. Moreover, there are cases where the grain temperature is much higher and yet the $\mathrm{H}_{2}$ formation rate appears high (Duley \& William 1984; Tielens \& Hollenbach 1985a,b; Habart et al. 2004; Allers et al. 2005). Molecular hydrogen has been observed in the Universe under various physical conditions. In diffuse clouds that typically have a density of $50 \mathrm{~cm}^{-3}$, a gas temperature of $\sim 100 \mathrm{~K}$, and a dust temperature of $15 \mathrm{~K}, \mathrm{H}_{2}$ forms at a rate of $1-3 \times 10^{-17} n_{\mathrm{o}} n(\mathrm{H}) \mathrm{cm}^{-3} \mathrm{~s}^{-1}$ where $n_{\mathrm{o}}$ is the total density and $n(\mathrm{H})$ the density of H-atoms (Jura 1974; Hollenbach et al. 1971). In molecular clouds and PDRs, the physical conditions at which $\mathrm{H}_{2}$ has been observed can cover a wide range of gas and grain temperatures $\left(100 \mathrm{~K} \leq T_{\text {gas }} \leq 1000 \mathrm{~K}\right.$; $10 \mathrm{~K} \leq T_{\text {dust }} \leq 100 \mathrm{~K}$ ). The $\mathrm{H}_{2}$ formation rate varies from $3 \times 10^{-17}$ to $1.5 \times 10^{-16} \mathrm{~cm}^{-3} \mathrm{~s}^{-1}$ for the PDRs associated with 
Orion Bar, NGC 2023, Chamaeleon, S140, IC 63, and Oph W (Habart et al. 2004; Allers et al. 2005). In active galaxies, i.e. in galaxies hosting an active galactic nucleus (AGN), $\mathrm{H}_{2}$ emission originates in regions with a gas temperature $\leq 2000 \mathrm{~K}$ (in NGC 1068, Rigopoulou et al. 2002) and with two dust components: one cold at $15-30 \mathrm{~K}$ and one warm at 50-70 K (Barthel \& van Bemmel 2003). Molecular hydrogen is also present in the early Universe, as testified by damped lyman alpha systems (DLAs). Ledoux et al. (2003) detected absorption lines of $\mathrm{H}_{2}$ toward several DLAs at high redshift $\left(z_{\mathrm{abs}} \geq 1.8\right)$, showing that $\mathrm{H}_{2}$ could form even in low-metallicity objects where the dust-to-gas ratio is as low as $1 / 20$ to $1 / 4$ of the Milky Way (Fall et al. 1989). All these observations show that molecular hydrogen forms with a high rate under various physical conditions. This has led to various attempts to examine the circumstances under which the efficiency $\epsilon\left(T_{\text {dust }}\right)$ could be close to 1 over an extended temperature range (Morisset et al. 2004, 2005; Cazaux \& Tielens 2002, 2004; Chang et al. 2005; Cuppen \& Herbst 2005).

The most recent approaches deal with the inhomogeneities of the interstellar grain surfaces. The interactions between the atoms and these surfaces are supposed to be only weak (Van der Waals) and are distributed in energy. An approach adopted by Chang et al. (2005) shows that, on inhomogeneous surfaces with distributions of $\mathrm{H}$-atom diffusion barriers and (physisorption) binding energies, and on mixed surfaces of olivine and carbon, the $\mathrm{H}_{2}$ formation efficiency remains large at dust temperatures relevant for diffuse clouds. More recently, Cuppen \& Herbst (2005) considered in their Monte Carlo simulations $\mathrm{H}_{2}$ formation on rough surfaces (where, unlike flat surfaces, there are height differences of at least several monolayers), based on the structure of olivine and amorphous carbon studied in laboratory experiments. Their results show an efficient formation of $\mathrm{H}_{2}$ until $T_{\text {dust }} \sim 40 \mathrm{~K}$ depending on the poorly known strengths of lateral bonds between $\mathrm{H}$ atoms and the (rough) surface. In their work, the presence of surface irregularities enhances the binding energy of hydrogen atoms but ignores a possible barrier for the $\mathrm{H}$ atoms to enter these sites, as it is the case for strong interactions.

The approach of Cazaux \& Tielens $(2002,2004)$ considers that, in addition to physisorption sites on the grain, there are also sites where $\mathrm{H}$ (or D) atoms can be chemisorbed with well depths of a large fraction of an electron volt. The presence of these two interactions between an atom and a surface has been calculated and measured by several authors for decades (Physisorption: Ghio 1980; Pirronello et al. 1997a,b, 1999. Chemisorption: experimentally: Güttler et al. 2004; Zecho et al. 2002, and theoretically: Aronowitch \& Chang 1980; Klose et al. 1992; Fromherz et al. 1993; Jeloaica \& Sidis 1999; Sha \& Jackson 2002, 2005). By considering these two interactions, one might have formation of $\mathrm{H}_{2}$ due to the association of a physisorbed $\mathrm{H}$ atom with a chemisorbed $\mathrm{H}$ atom. Since the chemisorbed $\mathrm{H}$ atom is more tightly bound, it will be less susceptible to evaporation, one can thus maintain $\mathrm{H}_{2}$ formation at grain temperatures higher than the 15-18 K mentioned above. Cazaux \& Tielens (2004) examined this possibility and find that one could indeed keep a high $\mathrm{H}_{2}$ formation efficiency up to temperatures of $20-30 \mathrm{~K}$ with moderate efficiency up to several hundred Kelvins. This seems more satisfactory, though this efficiency depends strongly (for $T_{\text {dust }} \geq 20-30 \mathrm{~K}$ ) on how easily an atom can chemisorb on an interstellar grain, and therefore, on the nature of the barrier against chemisorption. These uncertainties will be discussed in this paper.

More laboratory work on olivine and carbonaceous grains will definitely help in better constraining dust properties, but the actual structure of interstellar dust grains cannot be completely defined if model predictions cannot be tested against observations. As discussed above, the $\mathrm{H}_{2}$ formation process alone cannot be used for these purposes, given that a wide variety of models can reproduce the $\mathrm{H}_{2}$ abundance observed in diffuse clouds. We need to go one step forward and make other predictions besides the formation of $\mathrm{H}_{2}$. The simplest next step is to concentrate on the deuterated forms of molecular hydrogen ( $\mathrm{HD}$ and $\mathrm{D}_{2}$ ), the topic of the present paper. This has traditionally been considered unimportant because HD can form in the gas phase from $\mathrm{H}_{2}$ via ion-molecule reactions (and analogously $\mathrm{D}_{2}$ from $H D$ ). The gas phase route is expected to be more efficient than direct formation on grains if the $\mathrm{H}_{2}$ molecular fraction $f_{\mathrm{mol}}=\frac{2 n\left(\mathrm{H}_{2}\right)}{n \mathrm{H}}$ is larger than roughly 0.1 (Watson 1973). In a future paper, we will examine under which circumstances this is true and whether formation on dust grains makes an appreciable contribution to the observed HD in diffuse clouds. $\mathrm{D}_{2}$ has not been observed to date and we study its formation on grains as well as the possibility that it might be observable. The present paper focuses on surface processes, whereas in a future paper, surface chemistry will be coupled with gas phase chemistry and the model will be applied to different astrophysical environments.

In Sect. 2 of this paper, we describe the properties of dust surfaces, concentrating on graphitic and amorphous carbon grains, for which laboratory work is available. In Sect. 3 our model of surface chemistry is described, including the $\mathrm{H}$ and $\mathrm{D}$ rates of evaporation and mobility, rate equations, formation efficiencies. We also give some analytic approximations that reasonably reproduce our computed efficiencies for a limited range of grain temperature. In Sect. 4, we check the validity of the rate equation method against the Monte Carlo approach and compare it with previous work. A general discussion can be found in Sect. 5, whereas the main conclusions are listed in Sect. 6.

\section{Properties of the dust surface}

We concentrate here on graphitic (Gr) and amorphous carbon (AC) grains since olivine surfaces have been experimentally studied only at low temperatures (Pirronello et al. 1997a,b), making a characterisation of the strong interaction between the atoms and the surface very doubtful (Cazaux \& Tielens 2002). Grains rich in carbon, usually called carbonaceous in an amorphous form and graphitic in a crystalline form, have been the subject of a variety of experimental and theoretical studies. Graphite surfaces have been favoured for their simplest structures in order to perform both ab initio calculations and experiments. Theoretically, studies agree that there is a barrier between physisorbed and chemisorbed sites of $0.2 \mathrm{eV}$ (Jeloaica \& Sidis 1999; Sha \& Jackson 2002), making the filling of the chemisorbed sites very unlikely if the incoming atoms have low energies. Experiments at high temperatures on graphite have confirmed the presence of a high barrier against chemisorption (Zecho et al. 2002). Carbonaceous surfaces, on the other hand, present a very small barrier against chemisorption. Experiments performed by Menella et al. (2001) show that, for nano-sized carbon grains, low-energy $\mathrm{H}$ atoms can be bound efficiently to the surface $(\mathrm{C}-\mathrm{H}$ bonds $6 \%)$, showing that the barrier against chemisorption is small. Recent experiments by Zecho (private communication) prove that amorphous carbon surfaces present almost no barrier against chemisorption. Theoretically, Sha \& Jackson (2004) have determined a very small activation barrier for the adsorption of $\mathrm{H}$ atoms on the edges of graphitic nanostructures, and prove that $\mathrm{H}$ atoms can be chemisorbed easily on amorphous carbon surfaces. 


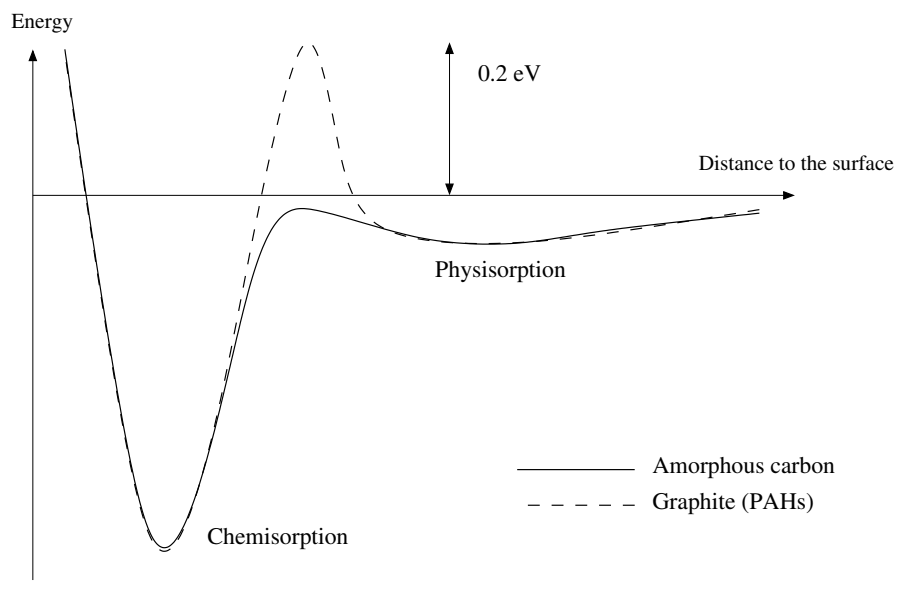

Fig. 1. Two possible types of carbonaceous grains.

It seems that carbon grains in the diffuse medium are a mixture of aliphatic and aromatic compounds (Pendleton \& Allamandola 2002). Big dust grains are thought exist in the form of carbonaceous grains, whereas small dust grains in the form of PAHs. In this work, we consider two types of carbon grains as illustrated in Fig. 1: (1) small grains ( $\leq 100 \AA$ ) , also called PAHs, have a surface similar to graphite. This surface presents a barrier against chemisorption of $0.2 \mathrm{eV}$ height and suppresses the formation of $\mathrm{H}_{2}$ at intermediate and high temperatures; (2) bigger grains have a surface similar to amorphous carbon surface. This surface presents a small (or no) barrier against chemisorption.

\section{Surface chemistry}

The formation of $\mathrm{H}_{2}$ and its deuterated forms on cold grains $\left(T_{\text {dust }} \leq 20 \mathrm{~K}\right)$ has been discussed by many authors and is still a controversial subject. While the Langmuir-Hinshelwood kinetics - the association of two atoms moving on the surface - is one of the main processes for the formation of these molecules at low grain temperatures (Pirronello et al. 1997a,b, 1999; Katz et al. 1999; Chang et al. 2005; Cuppen \& Herbst 2005), the Eley-Rideal mechanism - the association of an atom from the gas phase with a physisorbed atom - does not seem negligible (Morrisset et al. 2003). We consider these two mechanisms in our model and discuss their relative importance in Sect. 3.3.1.

\subsection{Interaction between $H, D$ atoms and the dust surface}

An atom from the gas phase hits the grain surface with a certain energy $k T_{\text {gas }}$ and, if stuck on the grain, it can become either physisorbed or chemisorbed. The probability that an atom arrive directly in a chemisorbed site is given by the transmission coefficient (to pass the barrier against chemisorption) integrated over an energy range described by the Boltzmann law (for details see Cazaux \& Tielens 2004). We call this probability $T_{\mathrm{pc}}\left(H_{\mathrm{gas}}\right)$ and $T_{\mathrm{pc}}\left(D_{\mathrm{gas}}\right)$ for $\mathrm{H}$ and $\mathrm{D}$ atoms, respectively. Once on the surface, the atom can move from its site to another site with a rate $\alpha_{i j}$, where $i$ is the initial site and $j$ is the next site that can be occupied. These rates, which describe the mobility of atoms on the surface, are calculated similarly to the $T_{\mathrm{pc}}\left(H_{\mathrm{gas}}\right)$ and $T_{\mathrm{pc}}\left(D_{\mathrm{gas}}\right)$, but they are multiplied by the oscillation factor of the atoms. Also, the Boltzmann energy distribution of an atom on a grain is centred on $T_{\text {dust }}$, while it is centred on $T_{\text {gas }}$ for an atom in the gas phase. The atom on the grain can evaporate with a rate $\beta\left(\mathrm{H}_{\mathrm{P}}\right)$ and $\beta\left(\mathrm{D}_{\mathrm{P}}\right)$ for physisorbed $\mathrm{H}$ and $\mathrm{D}$ atoms, and $\beta\left(\mathrm{H}_{\mathrm{C}}\right)$ and $\beta\left(\mathrm{D}_{\mathrm{C}}\right)$ for

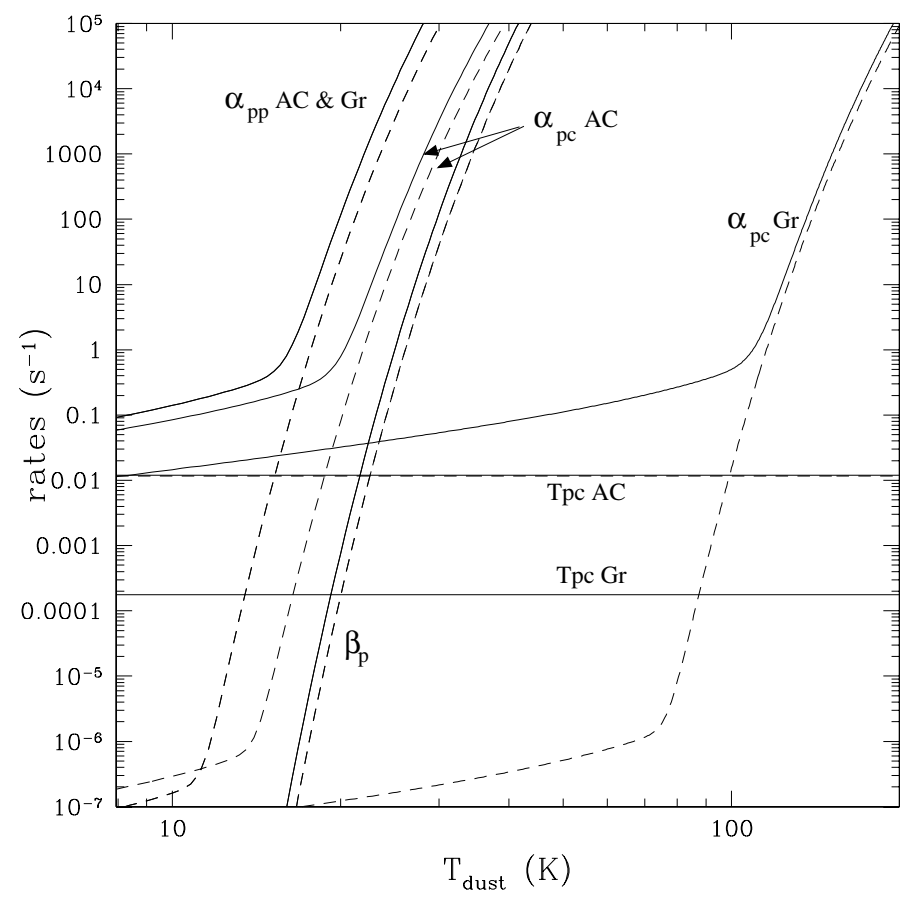

Fig. 2. Mobility and evaporation rate of the $H$ (solid lines) and $D$ (dashed lines) atoms on the graphitic surfaces (Gr) and amorphous carbon surfaces (AC).

chemisorbed $\mathrm{H}$ and $\mathrm{D}$ atoms. The $\mathrm{H}$ and $\mathrm{D}$ atoms move from a physisorbed to a chemisorbed site and between two physisorbed sites with a rate $\alpha_{\mathrm{pc}}$ and $\alpha_{\mathrm{pp}}$ respectively. A fraction $T_{\mathrm{pc}}$ of $\mathrm{H}$ and $\mathrm{D}$ atoms coming from the gas phase can directly chemisorb ( $1 \%$ on an amorphous carbon surface, and $0.02 \%$ on graphitic surfaces for a gas temperature of $100 \mathrm{~K}$ ). Figure 2 shows the various rates adopted in our model as a function of dust temperature and for the two different types of grains considered (see Sect. 2) The first thing to note in the figure is the huge difference between $\alpha_{\mathrm{pc}}$ for Gr and AC grains at $T_{\text {dust }}>20 \mathrm{~K}$, which shows weak dependence with dust temperature when tunnelling dominates ( $T_{\text {dust }}<20 \mathrm{~K}$ for AC and $<100 \mathrm{~K}$ for $\mathrm{Gr}$ ), whereas the dependence becomes exponential when thermal-hopping dominates. We also note the steep rise in $\alpha_{\mathrm{pp}}(\mathrm{D})$ at $T_{\text {dust }}>11 \mathrm{~K}$ and $\alpha_{\mathrm{pp}}(\mathrm{H})$ at $T_{\text {dust }}>14 \mathrm{~K}$ for $\mathrm{Gr}$ and AC grains.

\subsection{Rate equations}

The model described in Cazaux \& Tielens (2004) is reconsidered here, with the addition of deuterated species. The $\mathrm{H}_{2}, \mathrm{HD}$, and $\mathrm{D}_{2}$ formation mechanisms on grain surfaces are studied with the rate equation method based on the following assumptions:

1. the interaction atom/surface can be either weak (van der Waals interaction, also called physisorption) or strong (covalent bound also called chemisorption), with the assumption that there is a chemisorbed site for each physisorbed site;

2. an atom on the grain moves from one site to another by tunnelling effect or thermal hopping, according to its energy;

3. two atoms can associate to form a molecule following the Langmuir-Hinshelwood and Eley-Rideal mechanisms.

In this study, we add deuterium in our rate equation model and follow the population of physisorbed $\mathrm{H}\left(\mathrm{H}_{\mathrm{P}}\right)$ and $\mathrm{D}\left(\mathrm{D}_{\mathrm{P}}\right)$, chemisorbed $\mathrm{H}\left(\mathrm{H}_{\mathrm{C}}\right)$ and $\mathrm{D}\left(\mathrm{D}_{\mathrm{C}}\right)$, and the $\mathrm{H}_{2}, \mathrm{HD}$ and $\mathrm{D}_{2}$ 
molecules, which are physisorbed. The rate equations are written as

$$
\begin{aligned}
\dot{\mathrm{H}}_{\mathrm{P}}= & F_{\mathrm{H}}\left(1-T_{\mathrm{pc}} H_{\mathrm{gas}}\right)\left(1-\mathrm{H}_{\mathrm{P}}-\mathrm{D}_{\mathrm{P}}-\mathrm{HD}-\mathrm{H}_{2}-\mathrm{D}_{2}\right) \\
& -F_{\mathrm{H}}\left(1-T_{\mathrm{pc}} H_{\mathrm{gas}}\right) \mathrm{H}_{\mathrm{P}}-F_{\mathrm{D}}\left(1-T_{\mathrm{pc}} D_{\mathrm{gas}}\right) \mathrm{H}_{\mathrm{P}} \\
& -\alpha_{\mathrm{pc}}(\mathrm{H}) \mathrm{H}_{\mathrm{P}}-2 \alpha_{\mathrm{pp}}(\mathrm{H}) \mathrm{H}_{\mathrm{P}}{ }^{2}-\alpha_{\mathrm{pp}}(\mathrm{H}) \mathrm{H}_{\mathrm{P}} \mathrm{D}_{\mathrm{P}}-\alpha_{\mathrm{pp}}(\mathrm{D}) \mathrm{D}_{\mathrm{P}} \mathrm{H}_{\mathrm{P}} \\
& -\beta_{\mathrm{H}_{\mathrm{P}}} \mathrm{H}_{\mathrm{P}}
\end{aligned}
$$

$$
\begin{aligned}
\dot{\mathrm{D}}_{\mathrm{P}}= & F_{\mathrm{D}}\left(1-T_{\mathrm{pc}} D_{\mathrm{gas}}\right)\left(1-\mathrm{H}_{\mathrm{P}}-\mathrm{D}_{\mathrm{P}}-\mathrm{HD}-\mathrm{H}_{2}-\mathrm{D}_{2}\right) \\
& -F_{\mathrm{D}}\left(1-T_{\mathrm{pc}} D_{\mathrm{gas}}\right) \mathrm{D}_{\mathrm{P}}-F_{\mathrm{H}}\left(1-T_{\mathrm{pc}} H_{\mathrm{gas}}\right) \mathrm{D}_{\mathrm{P}} \\
& -\alpha_{\mathrm{pc}}(\mathrm{D}) \mathrm{D}_{\mathrm{P}}-2 \alpha_{\mathrm{pp}}(\mathrm{D}) \mathrm{D}_{\mathrm{P}}{ }^{2}-\alpha_{\mathrm{pp}}(\mathrm{D}) \mathrm{D}_{\mathrm{P}} \mathrm{H}_{\mathrm{P}}-\alpha_{\mathrm{pp}}(\mathrm{H}) \mathrm{H}_{\mathrm{P}} \mathrm{D}_{\mathrm{P}} \\
& -\beta_{\mathrm{D}_{\mathrm{P}}} \mathrm{D}_{\mathrm{P}} .
\end{aligned}
$$

These two equations describe the fractional population of $\mathrm{H}$ and $\mathrm{D}$ atoms in physisorbed sites, when a flux $F_{\mathrm{H}}$ and $F_{\mathrm{D}}$ of $\mathrm{H}$ and $\mathrm{D}$ atoms is sent to the surface. The first two lines of these equations describe the fraction of $\mathrm{H}$ and $\mathrm{D}$ atoms coming from the gas phase that physisorb on the grain. A fraction of $\mathrm{H}$ atoms $T_{\mathrm{pc}} H_{\text {gas }}$ and of D atoms $T_{\mathrm{pc}} D_{\text {gas }}$, goes directly in chemisorbed sites. These fractions are the amount of $\mathrm{H}$ and $\mathrm{D}$ atoms coming from the gas phase with an energy $T_{\text {gas }}$ that can cross the barrier against chemisorption. Also, a part of the incoming atoms going to physisorb arrive in an already filled physisorbed site and can either form a molecule directly (Eley-Rideal mechanism, 2nd lines of Eqs. (1) and (2)) if the site is occupied by an atom, or bounce back to the gas phase if the site is occupied by a molecule. The third line of these equations are dealing with Langmuir kinetic processes where the atoms diffuse on the surface from a site $i$ to a site $j$ with a rate $\alpha_{i j}(\mathrm{H})$ and $\alpha_{i j}(\mathrm{D})$. On these third lines, the first terms are the rate of atoms going to chemisorbed sites, the second, third, and fourth terms are the association of the physisorbed atoms with other physisorbed atoms, and the last term is the evaporation rate of the physisorbed atoms.

The equations describing the fractional population of $\mathrm{H}$ and $\mathrm{D}$ atoms in chemisorbed sites are:

$$
\begin{aligned}
\dot{\mathrm{H}}_{\mathrm{C}}= & F_{\mathrm{H}} T_{\mathrm{pc}} H_{\mathrm{gas}}\left(1-\mathrm{H}_{\mathrm{C}}-\mathrm{D}_{\mathrm{C}}\right)-F_{\mathrm{H}} T_{\mathrm{pc}} H_{\mathrm{gas}} \mathrm{H}_{\mathrm{C}} \\
& -F_{\mathrm{D}} T_{\mathrm{pc}} D_{\mathrm{gas}} \mathrm{H}_{\mathrm{C}}+\alpha_{\mathrm{pc}}(\mathrm{H}) \mathrm{H}_{\mathrm{P}}\left(1-\mathrm{H}_{\mathrm{C}}-\mathrm{D}_{\mathrm{C}}\right) \\
& -\alpha_{\mathrm{pc}}(\mathrm{H}) \mathrm{H}_{\mathrm{P}} \mathrm{H}_{\mathrm{C}}-\alpha_{\mathrm{pc}}(\mathrm{D}) \mathrm{D}_{\mathrm{P}} \mathrm{H}_{\mathrm{C}}-\beta_{\mathrm{H}_{\mathrm{C}}} \mathrm{H}_{\mathrm{C}} \\
\dot{\mathrm{D}}_{\mathrm{C}}= & F_{\mathrm{D}} T_{\mathrm{pc}} D_{\mathrm{gas}}\left(1-\mathrm{D}_{\mathrm{C}}-\mathrm{H}_{\mathrm{C}}\right)-F_{\mathrm{D}} T_{\mathrm{pc}} D_{\mathrm{gas}} \mathrm{D}_{\mathrm{C}} \\
& -F_{\mathrm{H}} T_{\mathrm{pc}} H_{\mathrm{gas}} \mathrm{D}_{\mathrm{C}}+\alpha_{\mathrm{pc}}(\mathrm{D}) \mathrm{D}_{\mathrm{P}}\left(1-\mathrm{D}_{\mathrm{C}}-\mathrm{H}_{\mathrm{C}}\right) \\
& -\alpha_{\mathrm{pc}}(\mathrm{D}) \mathrm{D}_{\mathrm{P}} \mathrm{D}_{\mathrm{C}}-\alpha_{\mathrm{pc}}(\mathrm{H}) \mathrm{H}_{\mathrm{P}} \mathrm{D}_{\mathrm{C}}-\beta_{\mathrm{D}_{\mathrm{C}}} \mathrm{D}_{\mathrm{C}} .
\end{aligned}
$$

The first lines represent the fraction of the $\mathrm{H}$ and $\mathrm{D}$ atoms that cross the barrier against chemisorption and directly populate the chemisorbed sites (with probability $T_{\mathrm{pc}}(\mathrm{H})$ and $T_{\mathrm{pc}}(\mathrm{D})$, respectively). One part of these atoms arrive in some already occupied sites and form a molecule (Eley-Rideal mechanism, 2nd terms first lines, and first terms second lines). In the last 2 lines, the 2nd terms account for physisorbed atoms arriving in empty chemisorbed sites, the second and third terms for the association of incoming physisorbed atoms with chemisorbed atoms, and the last term accounts for the evaporation of chemisorbed atoms.

The fractional population of $\mathrm{H}_{2}, \mathrm{D}_{2}$, and $\mathrm{HD}$ on grain surfaces is described by the following three equations:

$$
\begin{aligned}
\dot{\mathrm{H}}_{2}= & +\mu\left(\alpha_{\mathrm{pp}}(\mathrm{H}) \mathrm{H}_{\mathrm{P}}^{2}+\alpha_{\mathrm{pc}}(\mathrm{H}) \mathrm{H}_{\mathrm{P}} \mathrm{H}_{\mathrm{C}}\right)-\beta_{\mathrm{H}_{2}} \mathrm{H}_{2} \\
\dot{\mathrm{D}}_{2}= & +\mu\left(\alpha_{\mathrm{pp}}(\mathrm{D}) \mathrm{D}_{\mathrm{P}}^{2}+\alpha_{\mathrm{pc}}(\mathrm{D}) \mathrm{D}_{\mathrm{P}} \mathrm{D}_{\mathrm{C}}\right)-\beta_{\mathrm{D}_{2}} \mathrm{D}_{2} \\
\dot{\mathrm{HD}}= & +\mu\left(\alpha_{\mathrm{pp}}(\mathrm{H}) \mathrm{H}_{\mathrm{P}} \mathrm{D}_{\mathrm{P}}+\alpha_{\mathrm{pp}}(\mathrm{D}) \mathrm{D}_{\mathrm{P}} \mathrm{H}_{\mathrm{P}}+\alpha_{\mathrm{pc}}(\mathrm{H}) \mathrm{H}_{\mathrm{P}} \mathrm{D}_{\mathrm{C}}\right. \\
& \left.+\alpha_{\mathrm{pc}}(\mathrm{D}) \mathrm{D}_{\mathrm{P}} \mathrm{H}_{\mathrm{C}}\right)-\beta_{\mathrm{HD}} \mathrm{HD} .
\end{aligned}
$$

When a molecule is formed, because of the energy released during formation, a fraction $\mu$ stays on the grain surface, while a fraction $1-\mu$ spontaneously desorbs in the gas phase. The value of $\mu$ has been estimated from experiments (Katz et al. 1999; Cazaux \& Tielens 2002) and is considered to be identical for the different species (based on the experiments of HD desorption from Pirronello et al. 1997). The terms multiplied by $\mu$ describe the total formation rate of species remaining on the surface, whereas the last terms correspond to their evaporation rate. We consider in our approach that the molecules formed through the Eley-Rideal mechanism directly desorb in the gas phase. In the next section, we show that this approximation is reasonnable for grain temperatures higher than $10 \mathrm{~K}$.

To estimate the coverage of the different atoms and molecules on the grain, one needs to solve the 7 rate equations above, which are coupled. We point out here that the rate equation approach is valid when grains are covered by 1 or more of each species considered. This point is discussed in Sect. 4 of this paper.

\subsection{Formation rates and formation efficiencies}

The formation rate on dust surface of $\mathrm{H}_{2}, \mathrm{HD}$, and $\mathrm{D}_{2}$ that are released in the gas phase can be written as

$$
\begin{aligned}
R_{\mathrm{d}}\left(\mathrm{H}_{2}\right)= & F_{\mathrm{H}}\left(1-T_{\mathrm{pc}} H_{\mathrm{gas}}\right) \mathrm{H}_{\mathrm{P}}+F_{\mathrm{H}} T_{\mathrm{pc}} H_{\mathrm{gas}} \mathrm{H}_{\mathrm{C}} \\
& +(1-\mu)\left(\alpha_{\mathrm{pp}}(\mathrm{H}) \mathrm{H}_{\mathrm{P}}^{2}+\alpha_{\mathrm{pc}}(\mathrm{H}) \mathrm{H}_{\mathrm{P}} \mathrm{H}_{\mathrm{C}}\right)+\beta_{\mathrm{H}_{2}} \mathrm{H}_{2} \\
R_{\mathrm{d}}\left(\mathrm{D}_{2}\right)= & F_{\mathrm{D}}\left(1-T_{\mathrm{pc}} D_{\mathrm{gas}}\right) \mathrm{D}_{\mathrm{P}}+F_{\mathrm{D}} T_{\mathrm{pc}} D_{\mathrm{gas}} \mathrm{D}_{\mathrm{C}} \\
& +(1-\mu)\left(\alpha_{\mathrm{pp}}(\mathrm{D}) \mathrm{D}_{\mathrm{P}}^{2}+\alpha_{\mathrm{pc}}(\mathrm{D}) \mathrm{D}_{\mathrm{P}} \mathrm{D}_{\mathrm{C}}\right)+\beta_{\mathrm{D}_{2}} \mathrm{D}_{2} \\
R_{\mathrm{d}}(\mathrm{HD})= & F_{\mathrm{H}}\left(1-T_{\mathrm{pc}} H_{\mathrm{gas}}\right) \mathrm{D}_{\mathrm{P}}+F_{\mathrm{H}} T_{\mathrm{pc}} H_{\mathrm{gas}} \mathrm{D}_{\mathrm{C}} \\
& +F_{\mathrm{D}}\left(1-T_{\mathrm{pc}} D_{\mathrm{gas}}\right) \mathrm{H}_{\mathrm{P}}+F_{\mathrm{D}} T_{\mathrm{pc}} D_{\mathrm{gas}} \mathrm{H}_{\mathrm{C}} \\
& +(1-\mu)\left(\alpha_{\mathrm{pp}}(\mathrm{H}) \mathrm{H}_{\mathrm{P}} \mathrm{D}_{\mathrm{P}}+\alpha_{\mathrm{pp}}(\mathrm{D}) \mathrm{D}_{\mathrm{P}} \mathrm{H}_{\mathrm{P}}\right. \\
& \left.+\alpha_{\mathrm{pc}}(\mathrm{H}) \mathrm{H}_{\mathrm{P}} \mathrm{D}_{\mathrm{C}}+\alpha_{\mathrm{pc}}(\mathrm{D}) \mathrm{D}_{\mathrm{P}} \mathrm{H}_{\mathrm{C}}\right)+\beta_{\mathrm{HD}} \mathrm{HD}
\end{aligned}
$$

In these expressions, the terms with $F_{\mathrm{H}}$ and $F_{\mathrm{D}}$ represent the association of gas phase atoms with adsorbed atoms to form molecules via the Eley-Rideal mechanism. The other terms involve the association of two adsorbed atoms through the Langmuir-Hinshelwood kinetic. The formation efficiencies of the different molecules are $\epsilon\left(\mathrm{H}_{2}\right)=\frac{2 \times R_{\mathrm{d}}\left(\mathrm{H}_{2}\right)}{F_{\mathrm{H}}}, \epsilon\left(\mathrm{D}_{2}\right)=\frac{2 \times R_{\mathrm{d}}\left(\mathrm{D}_{2}\right)}{F_{\mathrm{D}}}$ and $\epsilon(\mathrm{HD})=\frac{R_{\mathrm{d}}(\mathrm{HD})}{F_{\mathrm{D}}}$.

\subsubsection{Eley-Rideal vs. Langmuir-Hinshelwood}

The efficiency of the formation of $\mathrm{H}_{2}, \mathrm{HD}$, and $\mathrm{D}_{2}$ for graphitic and amorphous carbon surfaces are shown in Fig. 3, for a density of $\mathrm{H}$ atoms of 100 atoms $\mathrm{cm}^{-3}$, a gas temperature of $100 \mathrm{~K}$, and a $\mathrm{D} / \mathrm{H}$ ratio of $2 \times 10^{-5}$. The different mechanisms involved in the formation of these molecules are presented. The Langmuir-Hinshelwood mechanism (LH) is the dominant process at any dust temperatures for amorphous carbon grains and at low grain temperatures $\left(T_{\text {dust }} \leq 25 \mathrm{~K}\right)$ for graphitic grains. Then, only in the case of graphitic grains and at higher grain temperatures $\left(T_{\text {dust }} \geq 25 \mathrm{~K}\right)$, the Eley-Rideal (ER) mechanism becomes important because most of the physisorbed atoms evaporate before populating the chemisorbed sites. The formation of molecules is then assured by the association of those atoms that chemisorb with the atoms from the gas phase that cross the barrier against chemisorption. 

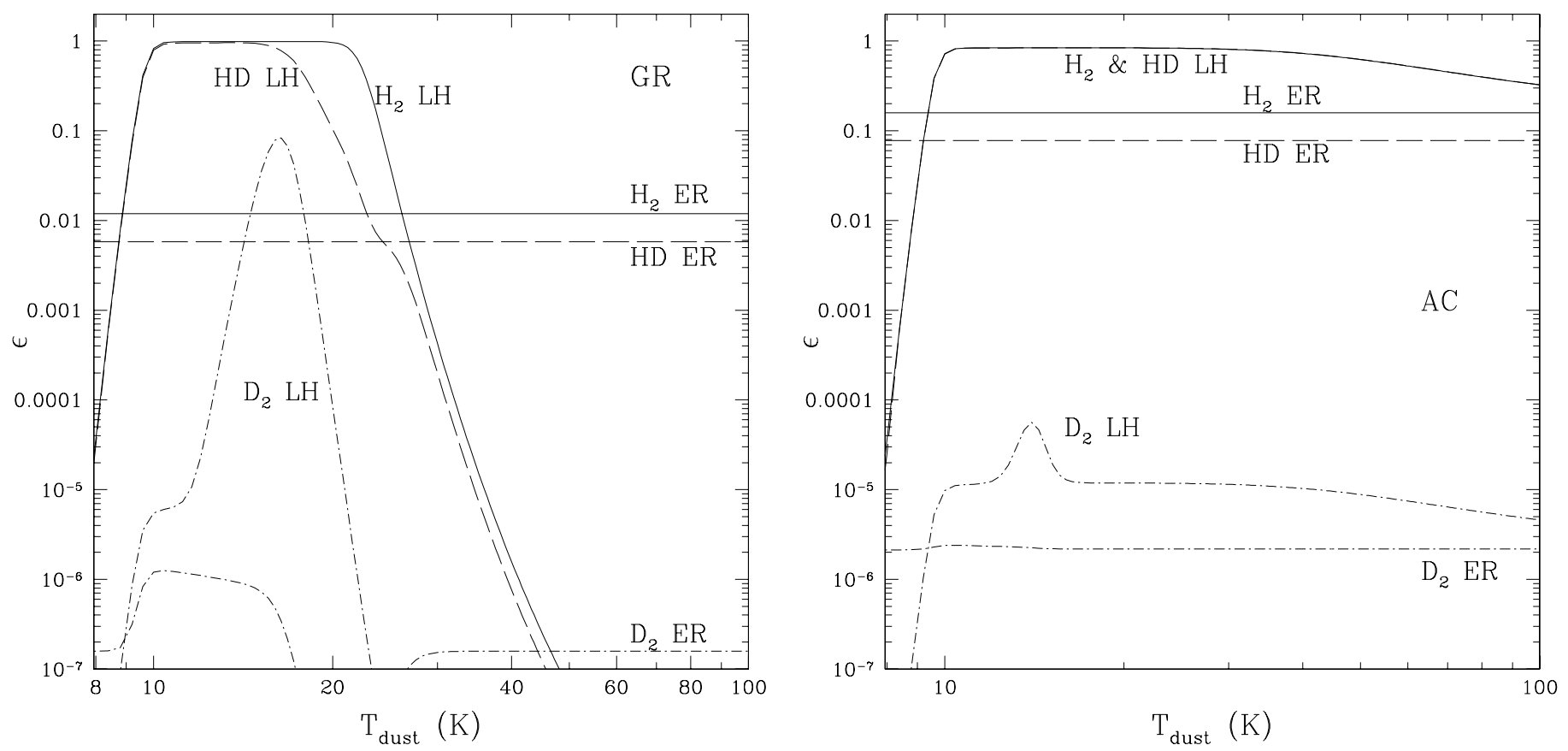

Fig. 3. $\mathrm{H}_{2}$ (solid lines), $\mathrm{HD}$ (dashed lines), and $\mathrm{D}_{2}$ (dotted dashed lines) formation efficiencies on graphitic surfaces (left) and amorphous carbon surfaces (right). LH: Langmuir-Hinshelwood kinetic and ER: the Eley-Rideal mechanism.

We consider in our model that molecules formed through the Eley-Rideal mechanisms are directly released into the gas phase. There is actually no experimental proof of such behaviour; but because the Eley-Rideal mechanism is efficient for grain temperatures higher than $25 \mathrm{~K}$, if some newly formed molecules remain on the surface, they will evaporate immediately. Therefore, considering $\mu=0$ for the Eley-Rideal mechanism is actually a reasonable approximation. In the case of very cold grains $\leq 9 \mathrm{~K}$, this approximation cannot be applied and a factor $\mu \neq 0$ should be considered.

A striking result is the enhanced $\mathrm{D}_{2}$ formation for a very narrow range of grain temperatures, while $\mathrm{H}_{2}$ and $\mathrm{HD}$ form efficiently for a much broader range. This $\mathrm{D}_{2}$ enhancement is much more important on graphitic surfaces than on amorphous carbon surfaces. Indeed, in the case of graphitic surfaces, at low surface temperatures, the high and narrow barrier against chemisorption allows $\mathrm{H}$ atoms to chemisorb through tunnelling, whereas most of the D atoms stay physisorbed. The $\mathrm{H}$ atoms, imprisoned in chemisorbed sites, free the physisorbed sites and let the physisorbed $\mathrm{D}$ atoms meet other physisorbed $\mathrm{D}$ atoms. This process makes the formation of $\mathrm{D}_{2}$ very efficient (for $T_{\text {dust }} \leq$ $20 \mathrm{~K})$. For higher grain temperatures, the physisorbed D evaporate which makes the $\mathrm{D}_{2}$ efficiency drop. In the case of carbonaceous grains, the barrier against chemisorption is smaller, and $\mathrm{H}$ and $\mathrm{D}$ atoms present similar mobilities (see Fig. 2). The physisorbed sites are also populated by $\mathrm{H}$ atoms. The formation of $\mathrm{D}_{2}$ is slightly enhanced around $T_{\text {dust }} \sim 15 \mathrm{~K}$ and follows the same behaviour as $\mathrm{H}_{2}$ and $\mathrm{HD}$ at higher grain temperatures.

The grain temperature at which $\mathrm{D}_{2}$ formation reaches its maximum also varies with the type of grain. In fact, the formation of $\mathrm{D}_{2}$ depends on the amount of physisorbed $\mathrm{D}$ atoms, which decreases with the physisorption-chemisorption mobility and evaporation rates, $\alpha_{\mathrm{pc}}(\mathrm{D})$ and $\beta_{\mathrm{D}_{\mathrm{p}}}$, both strongly dependent on $T_{\text {dust }}$ (see Fig. 2). For graphitic grains, at the highest $\mathrm{D}_{2}$ formation efficiency, the physisorbed $\mathrm{D}$ atoms evaporate more easily than they move into a chemisorbed site $\left(\alpha_{\mathrm{pc}}(\mathrm{D}) \leq \beta_{\mathrm{DP}_{\mathrm{p}}}\right)$. For amorphous carbon grains, on the other hand, the physisorbed
D atoms disappear by getting trapped in chemisorbed sites (for low $\mathrm{H}$ densities $\sim 1 \mathrm{~cm}^{-3}$ ) or by associating with a physisorbed $\mathrm{H}$ atom (only for high $\mathrm{H}$ densities $\sim 10^{4} \mathrm{~cm}^{-3}$ ). Therefore, the decrease in $\mathrm{D}_{2}$ efficiency, due to the disappearance of physisorbed D, occurs at lower grain temperatures for Gr than for AC grains.

The effect of the variation in gas temperature and $\mathrm{H}$ density is shown in Fig. 4, with a grain temperature set at $15 \mathrm{~K}$. The gas temperature does not have a big impact on the formation of $\mathrm{H}_{2}, \mathrm{HD}$, and $\mathrm{D}_{2}$ with the Langmuir-Hinshelwood mechanism. On the other hand, the gas temperature strongly increases the formation of the different molecules through the Eley-Rideal mechanism because the atoms can cross more easily the barrier against chemisorption.

As shown in Fig. 4, the $\mathrm{H}_{2}$ and $\mathrm{HD}$ formation efficiencies are constant with $\mathrm{H}$ density, while $\mathrm{D}_{2}$ formation efficiency is sensitive to its variation. The Langmuir-Hinshelwood kinetic is strongly affected by the density of $\mathrm{H}$ atoms. Indeed, for low $\mathrm{H}$ densities, the physisorbed sites are mainly populated with $\mathrm{D}$ atoms, and $\mathrm{D}_{2}$ formation is enhanced, while for high $\mathrm{H}$ densities, physisorbed sites are also populated by $\mathrm{H}$ atoms, making the formation of an HD molecule easier that for a $\mathrm{D}_{2}$ molecule. This effect is very different for the two types of grain since the barrier between physisorption and chemisorption sets the migration time of the atoms to move to a chemisorbed site, $1 / \alpha_{\mathrm{pc}}(\mathrm{H})$ and $1 / \alpha_{\mathrm{pc}}(\mathrm{D})$. If the physisorbed $\mathrm{D}$ atoms go to a chemisorbed site more easily than they evaporate $\left(\alpha_{\mathrm{pc}}(\mathrm{D}) \geq \beta_{\mathrm{D}_{\mathrm{P}}}\right)$ or than they meet a physisorbed $\mathrm{H}$ atom $\left(\alpha_{\mathrm{pc}}(\mathrm{D}) \geq \frac{\alpha_{\mathrm{p}}(\mathrm{H})}{\alpha_{\mathrm{pc}}(\mathrm{H})} F_{\mathrm{H}}\right.$ where this expression represents the flux of $\mathrm{H}$ atoms in physisorbed sites), then $\mathrm{D}$ atoms transit to chemisorbed sites and less $\mathrm{D}_{2}$ forms. If, on the other hand, the physisorbed $\mathrm{D}$ atoms have more chances to meet another physisorbed D than to chemisorb $\left(\frac{\alpha_{\mathrm{pp}}(\mathrm{D})}{\alpha_{\mathrm{pc}}(\mathrm{D})} F_{\mathrm{D}}\right.$ becomes $\left.\geq \alpha_{\mathrm{pc}}(\mathrm{D})\right)$ or to meet a physisorbed $\mathrm{H}\left(\frac{\alpha_{\mathrm{pp}}(\mathrm{D})}{\alpha_{\mathrm{pc}}(\mathrm{D})} F_{\mathrm{D}}\right.$ becomes $\left.\geq \frac{\alpha_{\mathrm{pp}}(\mathrm{H})}{\alpha_{\mathrm{pc}}(\mathrm{H})} F_{\mathrm{H}}\right)$, then $\mathrm{D}_{2}$ is formed more efficiently. For the two types of grains considered here, the $\mathrm{D}_{2}$ efficiency reaches its maximum 

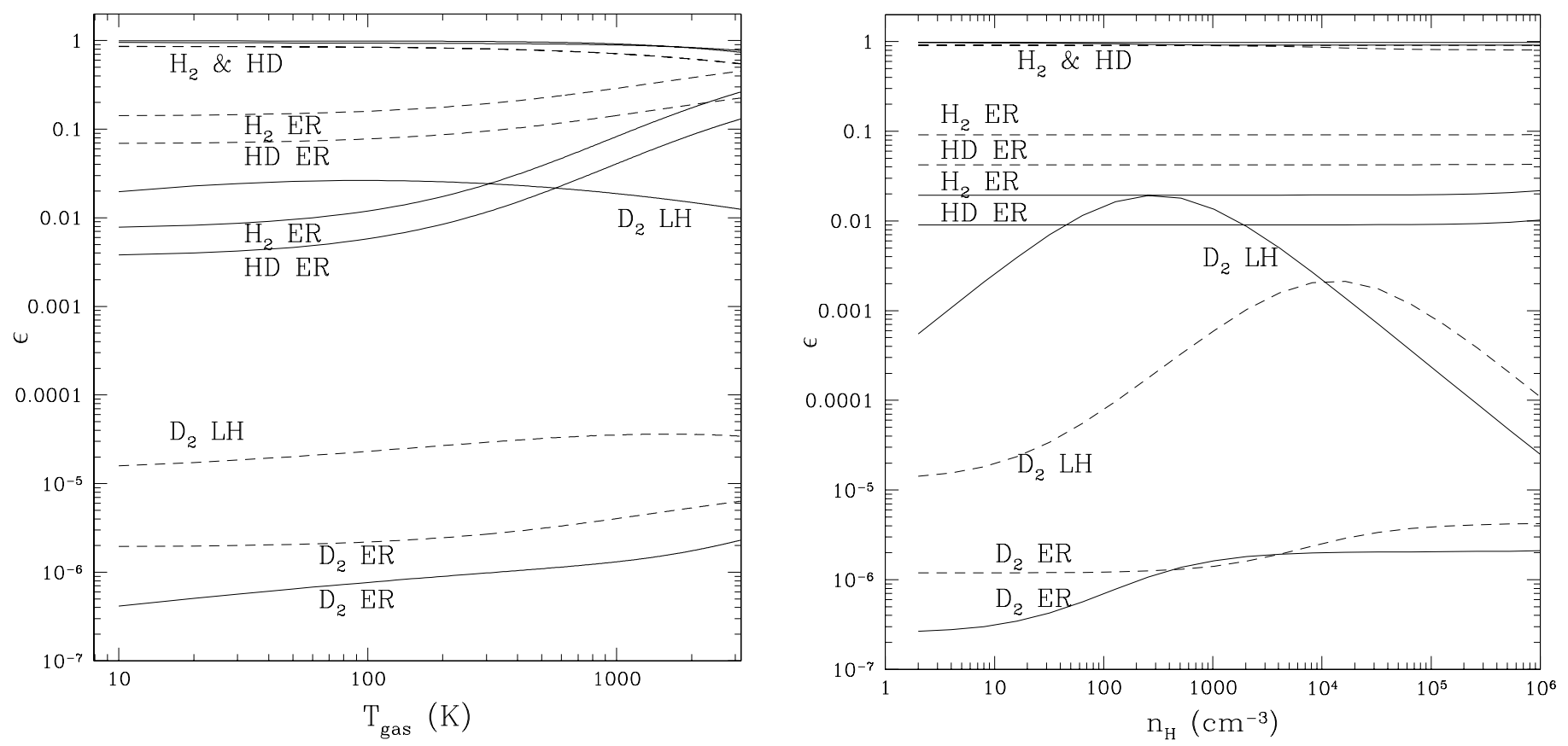

Fig. 4. $\mathrm{H}_{2}, \mathrm{HD}$, and $\mathrm{D}_{2}$ formation efficiencies on graphitic (solid lines) and amorphous carbon surfaces (dotted dashed lines). Left: efficiencies as a function of the gas temperature, with a density of $100 \mathrm{~cm}^{-3}$. Right: efficiencies as a function of the density $n \mathrm{H}$, with a gas temperature set at $100 \mathrm{~K}$.

at different $\mathrm{H}$ densities $\left(n \mathrm{H}=100\right.$ atoms $\mathrm{cm}^{-3}$ for $\mathrm{Gr}$ grains and $n \mathrm{H}=10^{4}$ atoms $\mathrm{cm}^{-3}$ for AC grains).

The effect of the variation in the $\mathrm{D} / \mathrm{H}$ ratio on the formation efficiencies of the different molecules is reported in Fig. 5, with a grain temperature set at $15 \mathrm{~K}$, a gas temperature at $100 \mathrm{~K}$, and a density of 100 atoms $\mathrm{cm}^{-3} \cdot \mathrm{H}_{2}$ does not depend on the $\mathrm{D} / \mathrm{H}$ ratio, while $\mathrm{HD}$ and $\mathrm{D}_{2}$ efficiencies show very different behaviours for $\mathrm{Gr}$ and $\mathrm{AC}$ grains. As discussed before, $\mathrm{Gr}$ grains, which have a very high barrier against chemisorption, segregate the $\mathrm{H}$ and $\mathrm{D}$ atoms by having most of its $\mathrm{H}$ chemisorbed and $\mathrm{D}$ physisorbed. This segregation favours deuteration.

\subsubsection{Analytic expressions}

Between dust temperatures of $10 \mathrm{~K}$ and $25 \mathrm{~K}$, as discussed previously, the Eley-Rideal mechanism can be neglected. The formation efficiency of $\mathrm{H}_{2}, \mathrm{HD}$, and $\mathrm{D}_{2}$ are calculated by setting the rate equations to zero (steady state conditions), and can be approximated as

$\epsilon_{\mathrm{H}_{2}}=2 \times \frac{\left(\alpha_{\mathrm{pp}}(\mathrm{H}) \mathrm{H}_{\mathrm{P}}^{2}+\alpha_{\mathrm{pc}}(\mathrm{H}) \mathrm{H}_{\mathrm{P}} \mathrm{H}_{\mathrm{C}}\right)}{F_{\mathrm{H}}}$

$\epsilon_{\mathrm{D}_{2}}=2 \times \frac{\left(\alpha_{\mathrm{pp}}(\mathrm{D}) \mathrm{D}_{\mathrm{P}}^{2}+\alpha_{\mathrm{pc}}(\mathrm{H}) \mathrm{H}_{\mathrm{P}} \mathrm{D}_{\mathrm{C}}\right)}{F_{\mathrm{D}}}$

$\epsilon_{\mathrm{HD}}=\frac{\left.\alpha_{\mathrm{pp}}(\mathrm{H})+\alpha_{\mathrm{pp}}(\mathrm{D})\right) \mathrm{H}_{\mathrm{P}} \mathrm{D}_{\mathrm{P}}+\alpha_{\mathrm{pc}}(\mathrm{H}) \mathrm{H}_{\mathrm{P}} \mathrm{D}_{\mathrm{C}}+\alpha_{\mathrm{pc}}(\mathrm{D}) \mathrm{D}_{\mathrm{P}} \mathrm{H}_{\mathrm{C}}}{F_{\mathrm{D}}}$.

These equations show that the formation of $\mathrm{H}_{2}$ occurs mainly through the association of a physisorbed and a chemisorbed atom. HD can be formed through the association of 2 physisorbed atoms, when the $\mathrm{H}$ atoms populate the physisorbed sites (high $\mathrm{H}$ densities of the medium and low grain temperatures) or through the association of physisorbed and chemisorbed atoms.
In the same way, $\mathrm{D}_{2}$ can be formed through the association of two physisorbed atoms, when physisorbed sites are mostly populated by D atoms, or through the association of a physisorbed and a chemisorbed D atom. The population of physisorbed atoms $\left(\mathrm{H}_{\mathrm{P}}\right.$ and $\left.\mathrm{D}_{\mathrm{P}}\right)$, chemisorbed atoms $\left(\mathrm{H}_{\mathrm{C}}\right.$ and $\left.\mathrm{D}_{\mathrm{C}}\right)$ as well as molecules $\left(\mathrm{H}_{2}, \mathrm{HD}\right.$, and $\left.\mathrm{D}_{2}\right)$ are determined in steady state conditions as

$$
\mathrm{H}_{\mathrm{P}}=\frac{F_{\mathrm{H}}}{\alpha_{\mathrm{pc}}(\mathrm{H})+\beta_{\mathrm{H}_{\mathrm{P}}}}
$$

$\mathrm{D}_{\mathrm{P}}=\frac{\alpha_{\mathrm{pc}}(\mathrm{D})+\alpha_{\mathrm{pp}}(\mathrm{H}) \mathrm{H}_{\mathrm{P}}+\sqrt{\left(\alpha_{\mathrm{pc}}(\mathrm{D})+\alpha_{\mathrm{pp}}(\mathrm{H}) \mathrm{H}_{\mathrm{P}}\right)^{2}+4 F_{\mathrm{D}} \alpha_{\mathrm{pp}}(\mathrm{D})}}{2 \alpha_{\mathrm{pp}}(\mathrm{D})}$

$\mathrm{H}_{\mathrm{C}}=\frac{1}{2}$

$\mathrm{D}_{\mathrm{C}}=\frac{\alpha_{\mathrm{pc}}(\mathrm{D}) \mathrm{D}_{\mathrm{P}}}{2 \alpha_{\mathrm{pc}}(\mathrm{H}) \mathrm{H}_{\mathrm{P}}}$

$\mathrm{H}_{2}=\frac{\mu \alpha_{\mathrm{pc}}(\mathrm{H}) \mathrm{H}_{\mathrm{P}} \mathrm{H}_{\mathrm{C}}}{\beta_{\mathrm{H}_{2}}}$

$\mathrm{HD}=\frac{\left.\mu\left(\alpha_{\mathrm{pp}}(\mathrm{H})+\alpha_{\mathrm{pp}}(\mathrm{D})\right) \mathrm{H}_{\mathrm{P}} \mathrm{D}_{\mathrm{P}}+\alpha_{\mathrm{pc}}(\mathrm{H}) \mathrm{H}_{\mathrm{P}} \mathrm{D}_{\mathrm{C}}+\alpha_{\mathrm{pc}}(\mathrm{D}) \mathrm{D}_{\mathrm{P}} \mathrm{H}_{\mathrm{C}}\right)}{\beta_{\mathrm{HD}}}$

$\mathrm{D}_{2}=\frac{\mu\left(\alpha_{\mathrm{pp}}(\mathrm{D}) \mathrm{D}_{\mathrm{P}}^{2}+\alpha_{\mathrm{pc}}(\mathrm{D}) \mathrm{D}_{\mathrm{P}} \mathrm{D}_{\mathrm{C}}\right)}{\beta_{\mathrm{D}_{2}}}$.

Half of the chemisorbed sites are occupied by hydrogen atoms because at low temperatures, the rate of physisorbed atoms to become chemisorbed is higher than their evaporation rate (as shown in Fig. 2). Therefore physisorbed atoms, will become 

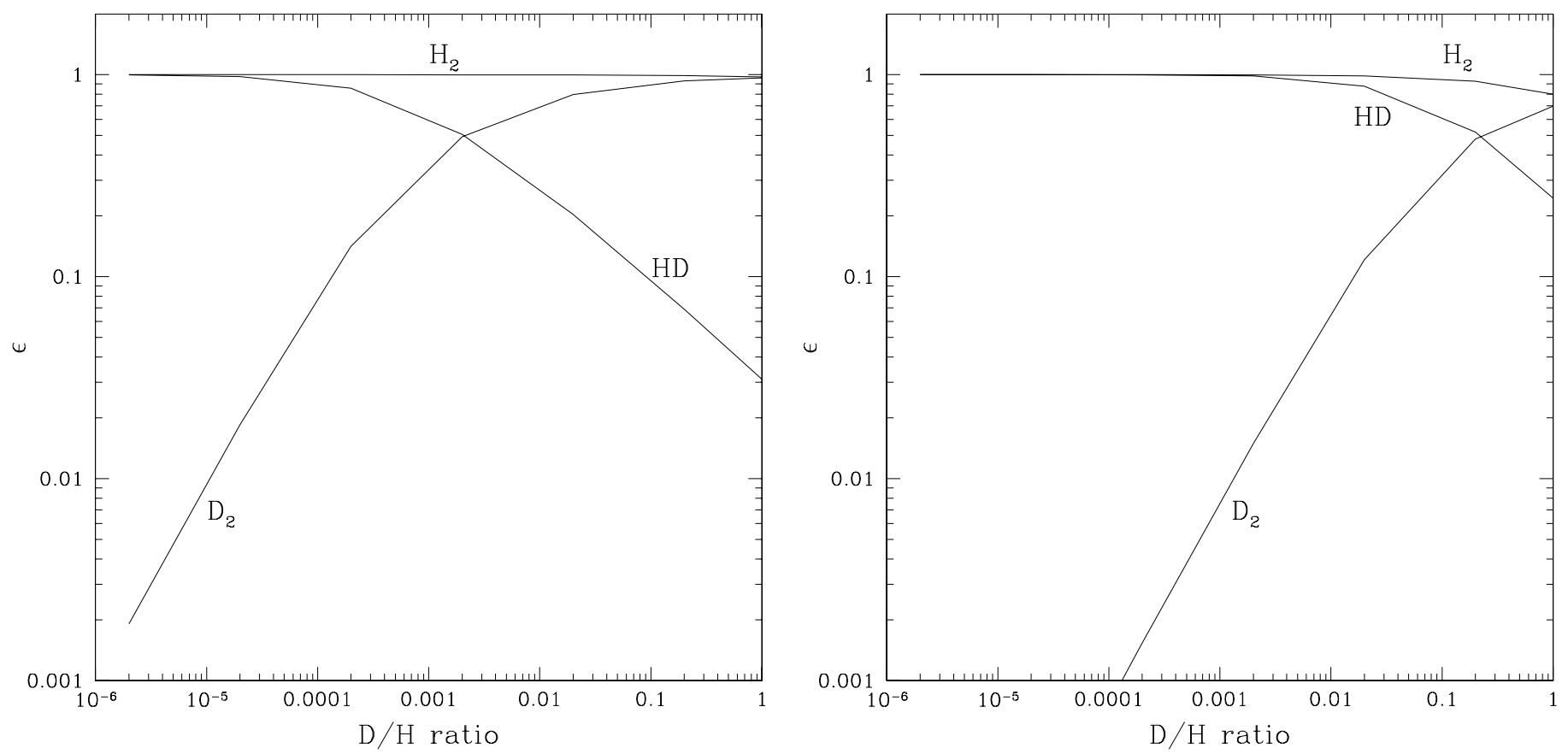

Fig. 5. HD and $\mathrm{D}_{2}$ formation efficiencies on graphitic (left panel) and amorphous carbon surfaces (right panel), as a function of the $\mathrm{D} / \mathrm{H}$ ratio. The grain temperature is set at $15 \mathrm{~K}$, the gas temperature at $100 \mathrm{~K}$, and the density at $100 \mathrm{~cm}^{-3}$.

trapped in chemisorbed sites, after visiting a number of $\frac{\alpha_{\mathrm{pp}}}{\alpha_{\mathrm{pc}}}$ of physisorbed sites. Above a certain temperature $(20 \mathrm{~K}$ for graphite and $50 \mathrm{~K}$ for amorphous carbon), these sites are filled through direct chemisorption.

The formation efficiencies of the different species for grain temperatures between 10 and $25 \mathrm{~K}$ can be written

$\epsilon_{\mathrm{H}_{2}}=\left[\frac{\alpha_{\mathrm{pc}}(\mathrm{H})+\beta_{\mathrm{H}_{\mathrm{p}}}}{\alpha_{\mathrm{pc}}(\mathrm{H})}\right]$

$\epsilon_{\mathrm{D}_{2}}=2 \frac{\mathrm{D}_{\mathrm{P}}^{2}}{F(\mathrm{D})}\left[\alpha_{\mathrm{pp}}(\mathrm{D})+\frac{\alpha_{\mathrm{pc}}(\mathrm{D})^{2}}{2 F(\mathrm{H})}\right]$

$\epsilon_{\mathrm{HD}}=\mathrm{D}_{\mathrm{P}}\left[\frac{\left(\alpha_{\mathrm{pp}}(\mathrm{H})+\alpha_{\mathrm{pp}}(\mathrm{D})\right) \mathrm{H}_{\mathrm{P}}+\alpha_{\mathrm{pc}}(\mathrm{D})}{F_{\mathrm{D}}}\right]$.

In Fig. 6, we show the validity of these approximations with our model. As discussed above, we consider a range of grain temperatures (10 $\mathrm{K} \leq T_{\text {dust }} \leq 25 \mathrm{~K}$ ) in which the Eley Rideal mechanism can be neglected. Because we are using a rate equation approach to calculate the formation rate of the different molecules, we need to define for which circumstances our approach is not valid. Indeed, rate equations cannot be used if the grain is covered by less than 1 species (Biham et al. 2001; Green et al. 2001; Caselli et al. 1998). In the case of hydrogen, rate equations are always valid because half of the chemisorbed sites are filled with hydrogen atoms. The problem is different for deuterium since most of the small grains are covered by less than $1 \mathrm{D}$ atom.

\section{Validity check of the rate equation method}

For very small grains, while the number of hydrogen on the surface (half of the chemisorbed sites) is always larger than one and therefore the rate equation method is always appropriate to describe $\mathrm{H}_{2}$ formation, the number of $\mathrm{D}$ atoms on the grain can be less than 1. In Fig. 7, we calculate the "critical" size of a grain for which one deuterium is present on its surface. These calculations have been performed for a density of $n \mathrm{H}=100 \mathrm{~cm}^{-3}$, a grain temperature of $15 \mathrm{~K}$, and for three different $\mathrm{D} / \mathrm{H}$ ratios: $2 \times 10^{-5}, 2 \times 10^{-3}$ and $2 \times 10^{-1}$ for graphitic grains (left panel) and amorphous carbon grains (right panel).

\subsection{Monte Carlo and approximations}

For grains below the critical size, the rate equation method cannot be used to follow the formation of $\mathrm{HD}$ and $\mathrm{D}_{2}$ on very small grains. We developed a Monte Carlo model in order to follow the formation of $\mathrm{HD}$ and $\mathrm{D}_{2}$ on these grains. In our model, the grain is seen as a squared grid, with the possibility, at each intersection, of having a chemisorbed and a physisorbed atom. We consider as before direct chemisorption, as well as Langmuir and Eley-Rideal mechanisms. When an atom comes from the gas phase onto this grid it can become physisorbed or chemisorbed, depending on its energy. If the site is already occupied, it can form a molecule that is released in the gas phase (we consider $\mu=0$, which is a valid approximation for a range of temperatures at which newly formed molecules staying on the surface thermally desorb). The position of the incoming atom on the grid is chosen randomly. Once on the grid, the atom can move from site to site according to its energy, and it follows a random walk. If two atoms arrive at the same site, they associate to form a molecule that is released in the gas phase. As discussed before, small grains $(\leq 100 \AA)$ are considered to have similar surfaces to graphite, and big grains similar to amorphous carbon.

Because the accretion of $\mathrm{D}$ on the grain is very low compared with the accretion of $\mathrm{H}$, the calculation times to form an HD and a $\mathrm{D}_{2}$ molecule are very important. To deal with this problem, we performed the Monte Carlo simulation for a $\mathrm{D} / \mathrm{H}$ ratio from 10 to 1000 times higher than the standard value $2 \times 10^{-5}$, and extrapolates these results for low $\mathrm{D} / \mathrm{H}$ ratios. The calculations are performed here for $T_{\text {dust }}=15 \mathrm{~K}, T_{\text {gas }}=100 \mathrm{~K}$ and $n \mathrm{H}=100 \mathrm{~cm}^{-3}$. Figure 8 shows the $\mathrm{HD}$ and $\mathrm{D}_{2}$ efficiencies for 

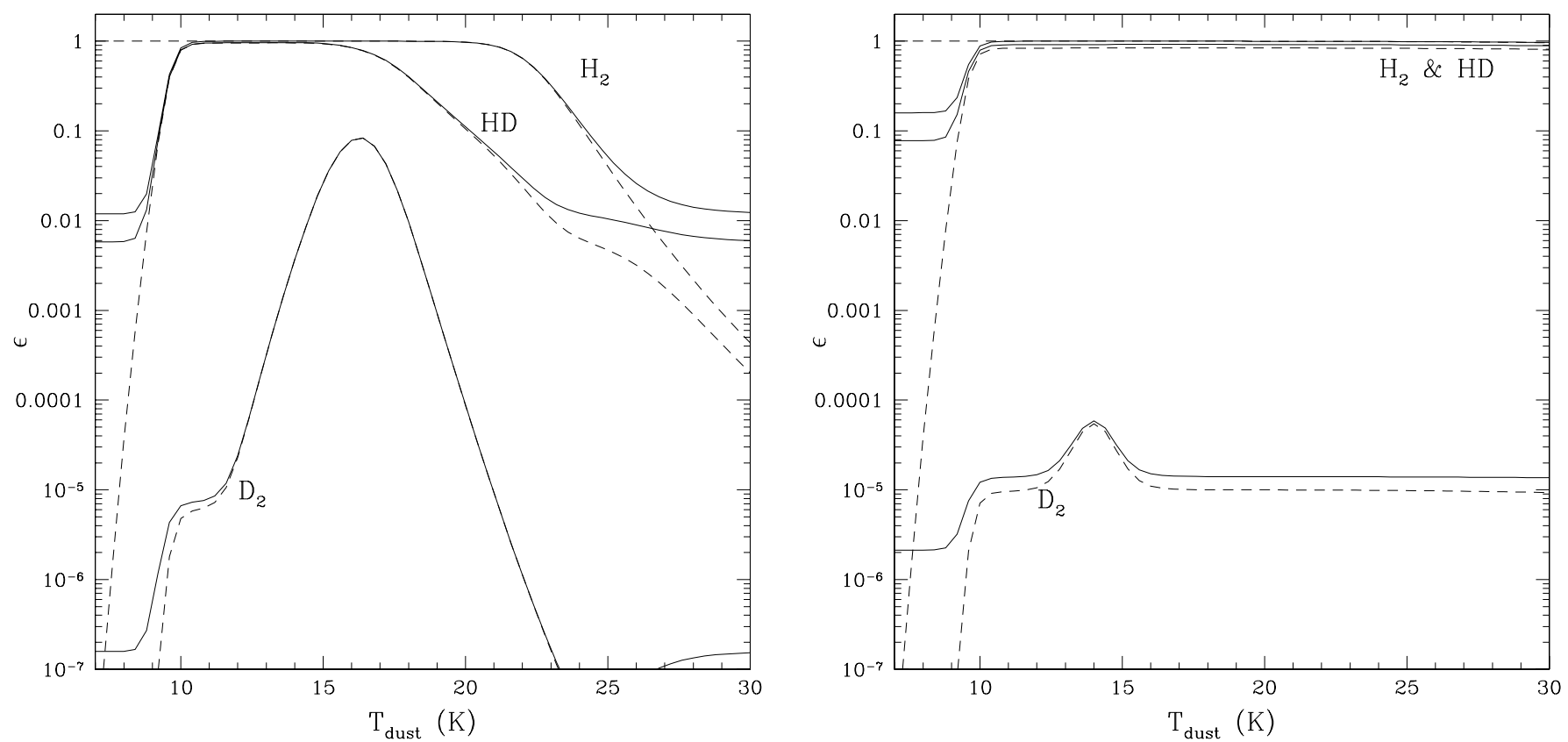

Fig. 6. $\mathrm{H}_{2}, \mathrm{HD}$, and $\mathrm{D}_{2}$ formation efficiencies on graphitic (left) and amorphous carbon (right) surfaces compared to our approximations (dashed lines).
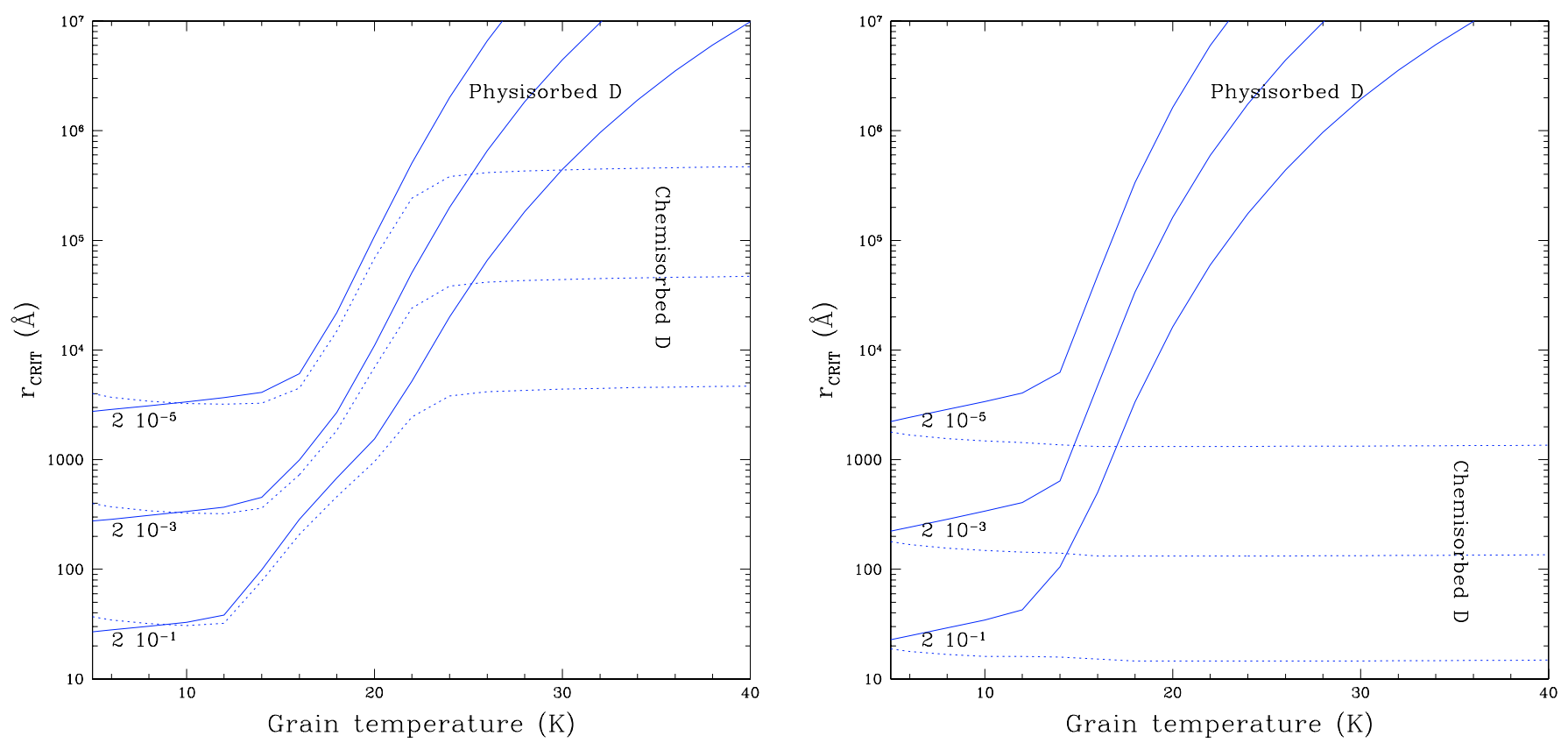

Fig. 7. Critical grain size for which a grain possesses at least one deuterium physisorbed and chemisorbed for graphitic (left panel) and carbonaceous (right panel) grains.

graphitic grain from 100 sites $(\sim 30 \AA)$ to $10^{7}$ sites $(\sim 1 \mu \mathrm{m})$ and for a $\mathrm{D} / \mathrm{H}$ ratio that varies from $2 \times 10^{-4}$ to $2 \times 10^{-1}$. Figure 9 shows these efficiencies for carbonaceous grains for a $\mathrm{D} / \mathrm{H}$ ratio of $2 \times 10^{-1}$ and $2 \times 10^{-3}$. For big grains, steady state and Monte Carlo simulations give the same results. As expected, when the number of physisorbed deuterium on the grain is less than one, the two methods diverge. This happens for a grain smaller than a critical size as determined in Fig. 7. Below this critical size, with decreasing grain sizes, the efficiency of $\mathrm{D}_{2}$ decreases, while the efficiency of HD increases. Indeed, on big grains, the number of physisorbed deuterium is higher than or equal to 1 , and a
D atom coming from the gas phase on the grain can meet another physisorbed deuterium. On small grains, on the other hand, the number of physisorbed deuterium can be less than 1 , and a deuterium atom coming from the gas phase on the grain can scout the surface before getting trapped in a chemisorbed site without meeting another deuterium. When getting chemisorbed, the deuterium can meet an $\mathrm{H}$ atom already present, or can wait for an $\mathrm{H}$ atom coming into the chemisorbed site. According to our calculations, as shown in Fig. 9 (right) and in Fig. 10 (right), association of physisorbed atoms on grain surfaces are dependent on the size of the grains, while association of physisorbed and 

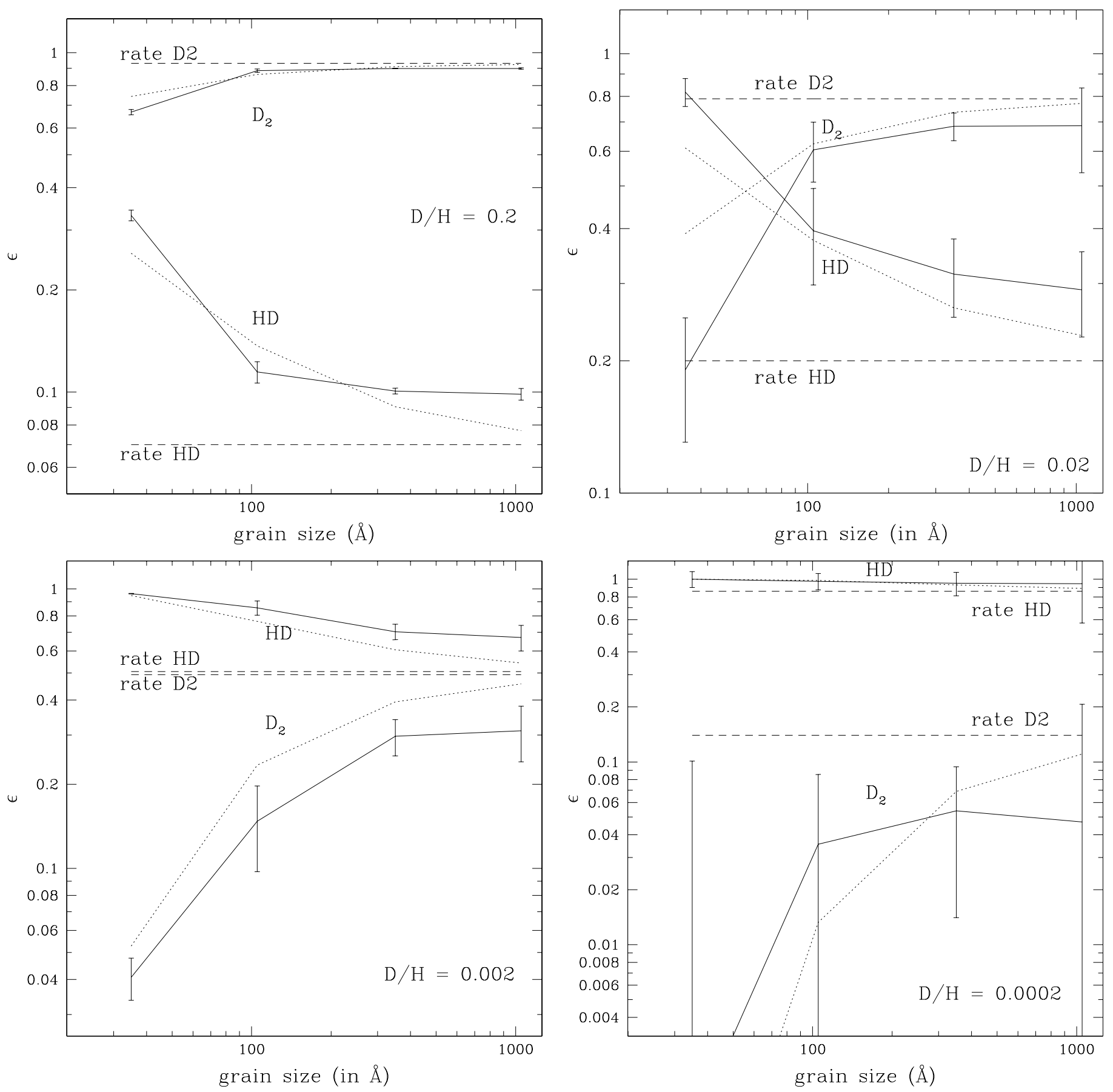

Fig. 8. Monte Carlo (solid lines) compared to rate equation (dashed lines) simulations and our approximations (dotted lines) for the HD and $\mathrm{D}_{2}$ formation efficiencies on graphitic surfaces. The $\mathrm{D} / \mathrm{H}$ ratio is 0.2 (top left), $2 \times 10^{-2}$ (top right), $2 \times 10^{-3}$ (bottom left), and $2 \times 10^{-4}$ (bottom right). The error bars represent the $95 \%$ confidence intervals.

chemisorbed atoms are independent of size. We derived an empirical formula in order to reproduce the formation efficiencies of $\mathrm{HD}$ and $\mathrm{D}_{2}$ with grain sizes:

$$
\begin{aligned}
\epsilon\left(\mathrm{D}_{2}\right) & =\epsilon_{\mathrm{SS}}\left(\mathrm{D}_{2}\right)_{\mathrm{P}+\mathrm{C}}+\epsilon_{\mathrm{SS}}\left(\mathrm{D}_{2}\right)_{\mathrm{P}+\mathrm{P}} \exp \frac{-1}{\sqrt{\mathrm{D} / \mathrm{H} * \text { nsites }}} \\
\epsilon(\mathrm{HD}) & =\epsilon_{\mathrm{SS}}(\mathrm{HD})+\epsilon_{\mathrm{SS}}\left(\mathrm{D}_{2}\right)-\epsilon\left(\mathrm{D}_{2}\right) \\
& =\epsilon_{\mathrm{SS}}(\mathrm{HD})+\epsilon_{\mathrm{SS}}\left(\mathrm{D}_{2}\right)_{\mathrm{P}+\mathrm{P}}\left(1-\exp \frac{-1}{\sqrt{\mathrm{D} / \mathrm{H} * \text { nsites }}}\right)
\end{aligned}
$$

where $\epsilon_{\mathrm{SS}}$ is the total formation efficiency in steady state (see Fig. 5), $\epsilon_{\mathrm{SS}}()_{\mathrm{P}+\mathrm{C}}$ is the formation efficiency through the association of physisorbed and chemisorbed atoms, and $\epsilon_{\mathrm{SS}}()_{\mathrm{P}+\mathrm{P}}$ the formation efficiency through the association of two physisorbed atoms. Efficiencies due to the formation of molecules through the association of 2 physisorbed atoms decreases with decreasing grain size. These approximations are compared to our Monte Carlo simulation in Figs. 8 and 9. The error bars in our Monte Carlo simulations are obtained by repeating the calculations at least twice, depending on the CPU times required. The mean values are calculated together with the standard deviation. This latter quantity is multiplied by the appropriate student variable and the result represents the half confidence interval at the critical risk of $5 \%$ (95\% confidence interval). 

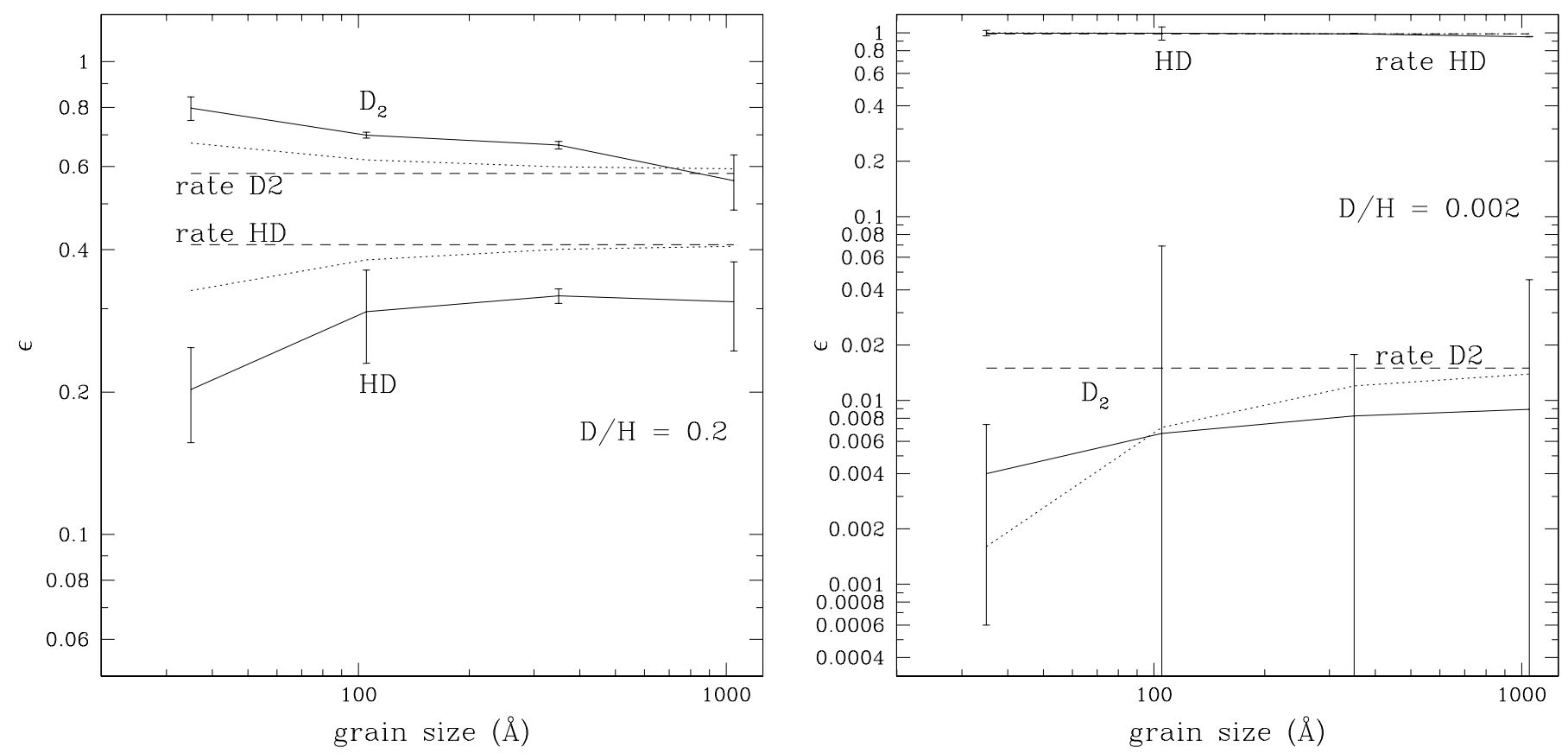

Fig. 9. Monte Carlo (solid lines) compared to rate equations simulations (dashed lines) and our approximations (dotted lines) for the HD and $\mathrm{D}_{2}$ formation efficiencies on amorphous carbon grains. The $\mathrm{D} / \mathrm{H}$ ratio is $2 \times 10^{-1}$ (left) and $2 \times 10^{-3}$ (right). The error bars represent the $95 \%$ confidence intervals.
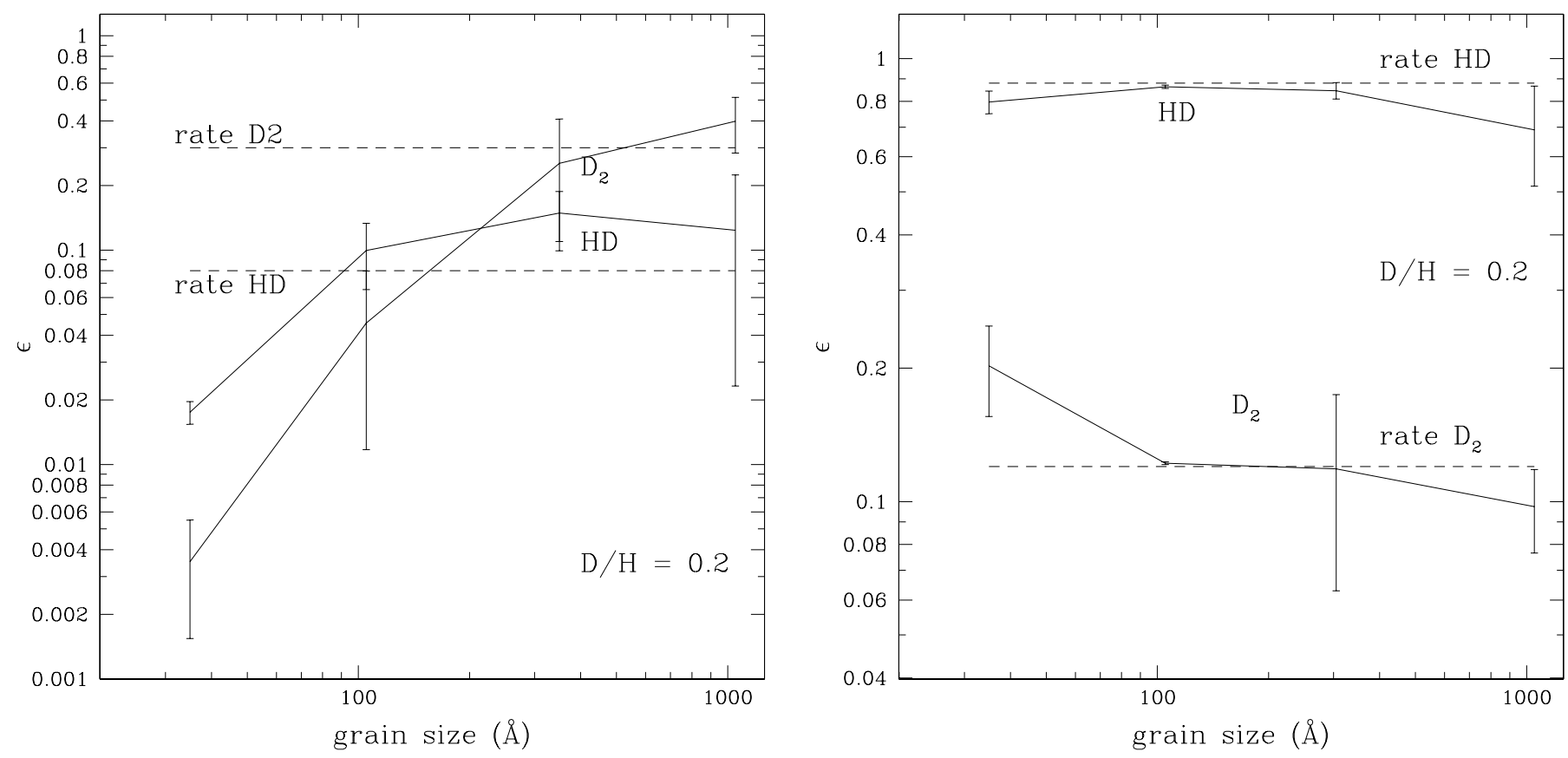

Fig. 10. Monte Carlo (solid lines) compared to rate equations simulations (dashed lines) for the $\mathrm{HD}$ and $\mathrm{D}_{2}$ formation efficiencies at higher grain temperatures. Left panel: graphitic surfaces at $20 \mathrm{~K}$. Right panel: carbonaceous surfaces at $25 \mathrm{~K}$. The error bars represent the $95 \%$ confidence intervals.

\subsection{Comparison with previous work}

Lipshtat et al. (2004) has also studied the formation of HD and $\mathrm{D}_{2}$ on grain surfaces. Their work differs from ours in several respects. First, their study considers only physisorbed sites and, as a consequence, they find $\mathrm{H}_{2}$ formation to be relatively inefficient at temperatures as low as $18 \mathrm{~K}$ (though note the efficiency is close to 1 below $16 \mathrm{~K}$ ). Second, they consider the formation of $\mathrm{H}_{2}, \mathrm{HD}$, and $\mathrm{D}_{2}$ on grains as small as $50 \AA$ with a masterequation approach, and integrate over a realistic grain size distribution. Their conclusions are that the production of the different molecules decreases with grain sizes. Also, when integrated over a wide range of grain sizes, the ratio of the production of $\mathrm{HD}$ over that of $\mathrm{H}_{2} R(\mathrm{HD}) / R\left(\mathrm{H}_{2}\right)$ and $\mathrm{D}_{2}$ over $\mathrm{H}_{2}$ $R\left(\mathrm{D}_{2}\right) / R\left(\mathrm{H}_{2}\right)$ can be enhanced by a factor as high as $44(78)$ for HD $\left(\mathrm{D}_{2}\right)$ (but sensitive to $T_{\text {dust }}$ ). This enhancement is due to a decrease in the production of $\mathrm{H}_{2}$.

Our results differ in that, as a consequence of the presence of chemisorbed sites, we find almost 100 percent efficiency in both $\mathrm{H}_{2}$ and $\mathrm{HD}$ formation (see Fig. 3), as long as the formation 
is made through the association of physisorbed and chemisorbed atoms. With our model, $\mathrm{H}_{2}$ formation is independent of the size of the grains. $\mathrm{D}_{2}$, which is mostly formed through the association of physisorbed atoms, has an efficiency that is grain-size dependent. The efficiency of $\mathrm{D}_{2}$ formation from Figs. 3 and 4 can be enhanced by 3000 for graphitic grains and a factor of 100 for carbonaceous grains. Also, using a Monte Carlo simulation, we show that the formation of $\mathrm{D}_{2}$ decreases with decreasing grain sizes, while the formation of HD increases. The production of these molecules integrated over a range of grain sizes is discussed in the next section.

\section{Discussion}

Density functional theory (DFT) calculations have shown that an $\mathrm{H}$ atom gets chemisorbed on graphitic surfaces atop a $\mathrm{C}$ atom, which has to move from the surface towards this adsorbate (Jeloaica \& Sidis 1999; Sha \& Jackson 2002). This phenomenon is called puckering, and it creates a barrier against chemisorption of $0.2 \mathrm{eV}$. Recent studies by Rougeau et al. (2006) and Hornekaer et al. (2006) have shown that once an $\mathrm{H}$ atom is chemisorbed on graphite, and therefore a $\mathrm{C}$ atom has puckered out of the plane, the next $\mathrm{H}$ atom can chemisorb in certain neighbouring sites (para site) without any barrier. Another study by Bachellerie et al. (2007) shows that, once an $\mathrm{H}$ atom is chemisorbed in a para site, a second $\mathrm{H}$ atom can also chemisorb at the same site without barrier and form a molecule. These results are essential in the formation of molecules when the chemisorbed atoms are involved. Because rate equations do not take the detailed structure of the surface into account, we could not consider this phenomenon. In this study, we developed a Monte Carlo simulation to understand how the formation of $\mathrm{H}_{2}$, $\mathrm{HD}$, and $\mathrm{D}_{2}$ changes with the size of the grain. We compared these simulations to the rate equations model, and therefore had to consider the same surface without taking the properties of the para sites into account. In a future work we will incorporate these properties into our Monte Carlo simulations and see how the formation efficiencies of $\mathrm{H}_{2}$ and its deuterated forms differ if we consider the para sites. The first effect of the inclusions of the para sites in our model should be a more efficient $\mathrm{H}_{2}$ formation rate at temperatures higher than $20 \mathrm{~K}$.

To summarise the results obtained so far for $\mathrm{D}_{2}$, Fig. 11 shows the variation in the $D_{2}$ formation efficiency with dust temperature for the following parameters: $n\left(\mathrm{H}_{2}\right)=1000 \mathrm{~cm}^{-3}$ and $\mathrm{D} / \mathrm{H}=2 \times 10^{-5}$. The efficiency of $\mathrm{D}_{2}$ formation varies strongly from one kind of surface to another. If we consider surfaces where only physisorption is possible, the formation of $\mathrm{D}_{2}$ is very low, as discussed in Lipshtat et al. (2004). The inclusion of chemisorbed sites in our model increases the formation efficiency of $\mathrm{D}_{2}$ because of the different behaviours of $\mathrm{H}$ and $\mathrm{D}$ on grain surfaces. $\mathrm{H}$ atoms are more mobile and will get easily trapped on chemisorbed sites, whereas D will mostly stay in physisorbed sites. Therefore, the surface structure has a big impact on the formation of $\mathrm{D}_{2}$. Surfaces, such as graphitic, present a very high barrier against chemisorption. $\mathrm{H}$ atoms will overcome this barrier by tunnelling, while D will tunnel much less efficiently and stay in the physisorbed sites. Since $\mathrm{D}_{2}$ mostly forms through the association of physisorbed atoms, this segregation favours the formation of $\mathrm{D}_{2}$. Carbonaceous grains, on the other hand, present a very low barrier against chemisorption, making the behaviour of $\mathrm{H}$ and $\mathrm{D}$ similar. The formation efficiency of $\mathrm{D}_{2}$ present a small enhancement. Therefore, deuteration will be more efficient on graphitic surfaces (small grains) than on amorphous carbon surfaces (big grains).

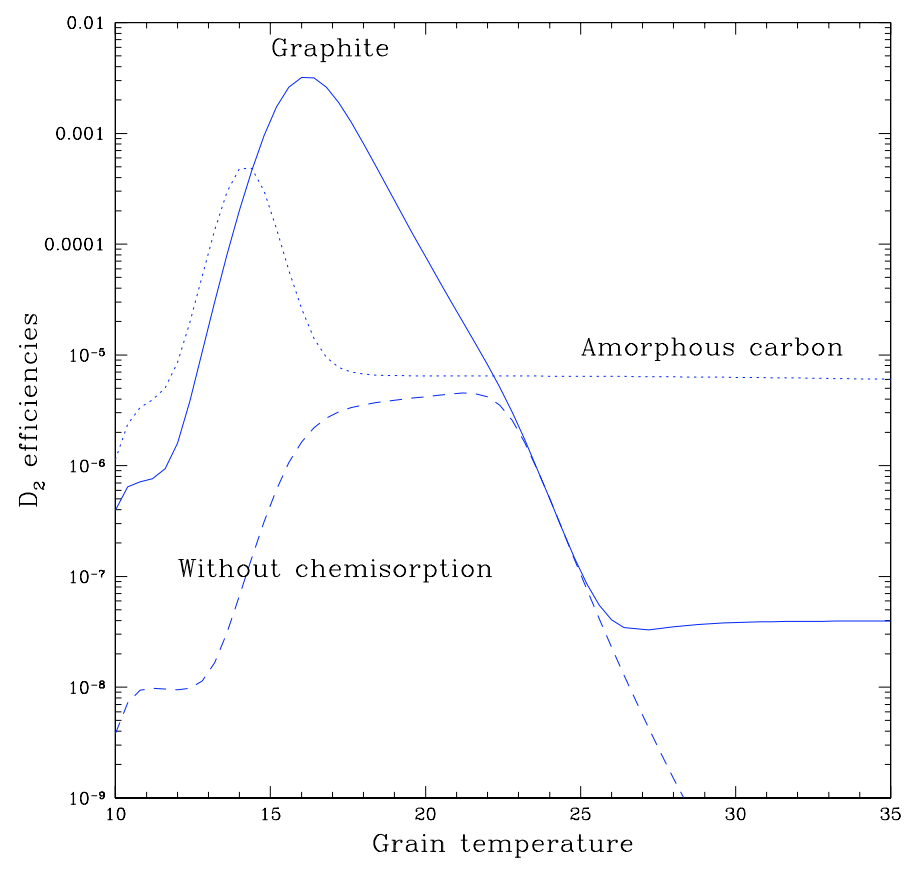

Fig. 11. Formation efficiency of $\mathrm{D}_{2}$ molecules for graphite and amorphous carbon and for surfaces without chemisorption sites, such as icy grains.

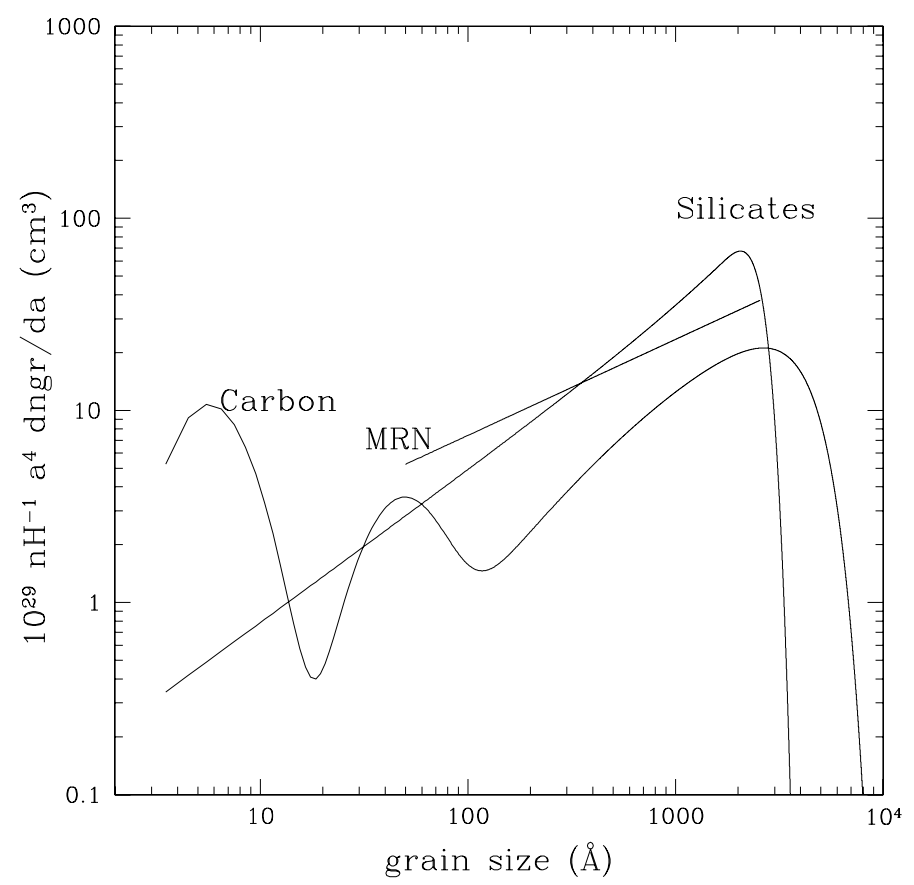

Fig. 12. Grain size distribution for carbon and silicate grains, as estimated by Weintgartner \& Draine (2001). Small grains $(\leq 100 \AA)$ are similar to PAHs, and big ones similar to amorphous carbon grains.

We consider a grain size distribution, as described by Weintgartner \& Draine (2001), to predict the formation rate of $\mathrm{H}_{2}, \mathrm{HD}$ and $\mathrm{D}_{2}$ (in $\mathrm{cm}^{-3} \mathrm{~s}^{-1}$ ). This distribution is represented Fig. 12. We calculated the total cross section of the grains for graphitic grains and carbonaceous grains. We considered that PAHs and very small grains $(\leq 100 \AA)$ have similar surfaces to graphitic surfaces, and that bigger grains have surfaces similar to carbonaceous surfaces. Then, we integrated the efficiencies for the formation of the different molecules, with our correction for 


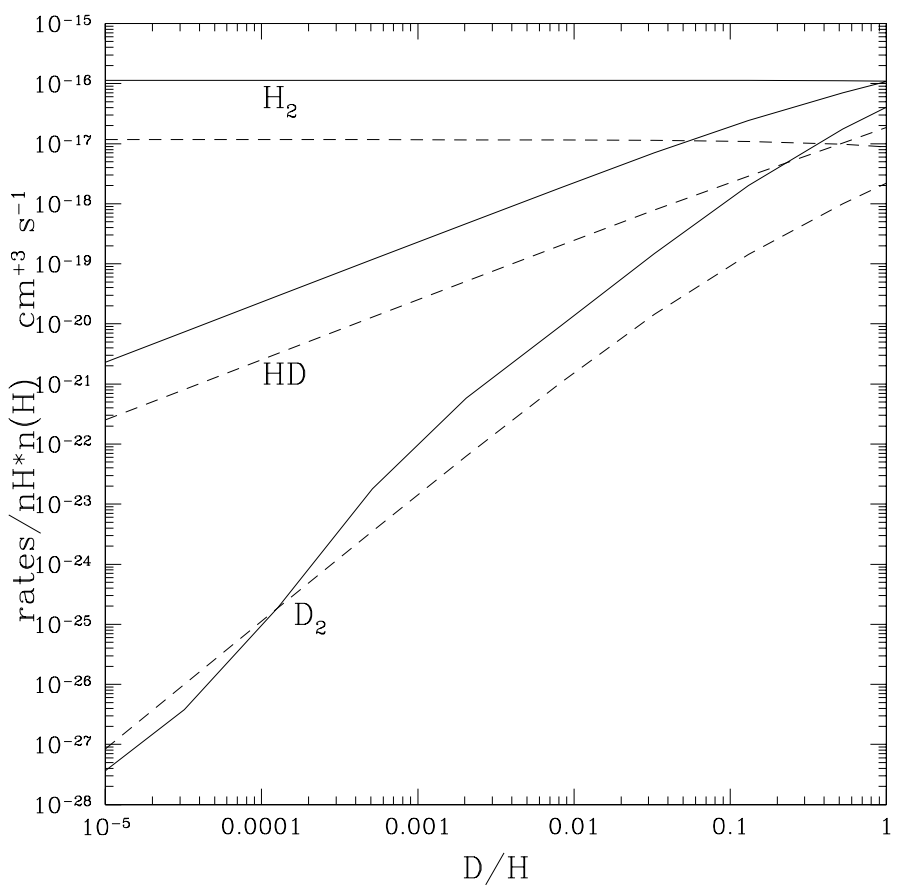

Fig. 13. Formation rate of $\mathrm{H}_{2}, \mathrm{HD}$, and $\mathrm{D}_{2}$ on small grains and PAHs (solid lines) and big grains (dashed lines) as a function of the $\mathrm{D} / \mathrm{H}$ ratio.

small sizes, over the range of grain sizes, following the distribution of Weintgartner \& Draine (2001). Figure 13 shows how the formation of these species depends on the $\mathrm{D} / \mathrm{H}$ ratio for graphitic surfaces and for carbonaceous grains, for a grain temperature of $15 \mathrm{~K}$, a gas temperature of $100 \mathrm{~K}$, and a density of $100 \mathrm{~cm}^{-3}$. The formation of $\mathrm{H}_{2}$ and HD under these circumstances comes mostly from the contribution of small grains ( $\mathrm{Gr}$ grains). On the other hand, $\mathrm{D}_{2}$ is mostly formed on big grains (AC grains), for low $\mathrm{D} / \mathrm{H}$ ratios $\left(\mathrm{D} / \mathrm{H} \leq 10^{-4}\right)$, and on small grains ( $\mathrm{Gr}$ grains) for higher D/H ratio. Figure 14 presents the same results as a function of the density, for a grain temperature fixed at $15 \mathrm{~K}$ and a gas temperature of $100 \mathrm{~K}$. While the formation of $\mathrm{H}_{2}$ and $\mathrm{HD}$ is mostly due to the small grain contribution for any $n(\mathrm{H}), \mathrm{D}_{2}$ is mainly produced on small grains at low densities and on big grains at high densities. Figure 15 presents the formation rate of the different species as a function of the grain temperatures, for a gas temperature of $100 \mathrm{~K}$, a density of $100 \mathrm{~cm}^{-3}$, and a $\mathrm{D} / \mathrm{H}$ ratio of $2 \times 10^{-5}$. First, it seems clear that the formation of $\mathrm{H}_{2}$ comes from the contribution of small grains at low grain temperatures, and of big grains at higher grain temperature. These two contributions, added together, reproduce the formation rates observed in different PDRS quite well, as described by Habart et al. (2003). Small grains contribute strongly to the formation of $\mathrm{H}_{2}$ and $\mathrm{HD}$ at low grain temperatures. Then, for temperatures higher than $\sim 20 \mathrm{~K}$, these molecules are formed mostly on big grains. At these higher temperatures, the rate of $\mathrm{H}_{2}$ formation drops to $10^{-17} n \mathrm{H} n(\mathrm{H}) \mathrm{cm}^{-3} \mathrm{~s}^{-1}$. This value is similar to the one observed in PDRs where warm dust grains are present as in NGC 2023 and the Orion Bar (Habart et al. 2004; Allers et al. 2005). For the case of $\mathrm{D}_{2}$, for standard $\mathrm{D} / \mathrm{H}$, its formation comes from the big grains.

In the interstellar medium, dust is heated by photons. Dust grains receive a short heat impulse, resulting in temperature fluctuations, especially for small grains. This phenomenon has been described by Draine \& Li (2001) who show that grains of the size of $50 \AA$ can fluctuate from 5 to $40 \mathrm{~K}$, but still spend most of their life $(90 \%)$ at temperatures below $20 \mathrm{~K}$. For smaller grains

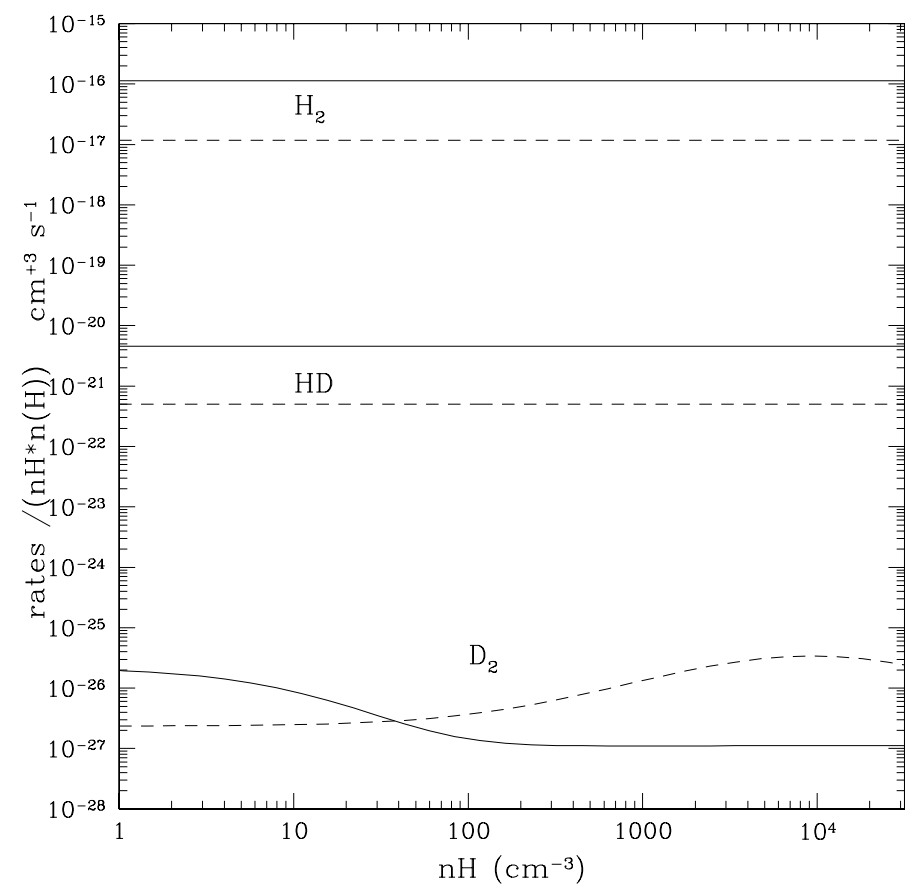

Fig. 14. Formation rate of $\mathrm{H}_{2}, \mathrm{HD}$, and $\mathrm{D}_{2}$ on small grains and PAHs (solid lines) and big grains (dashed lines) as a function of the density.

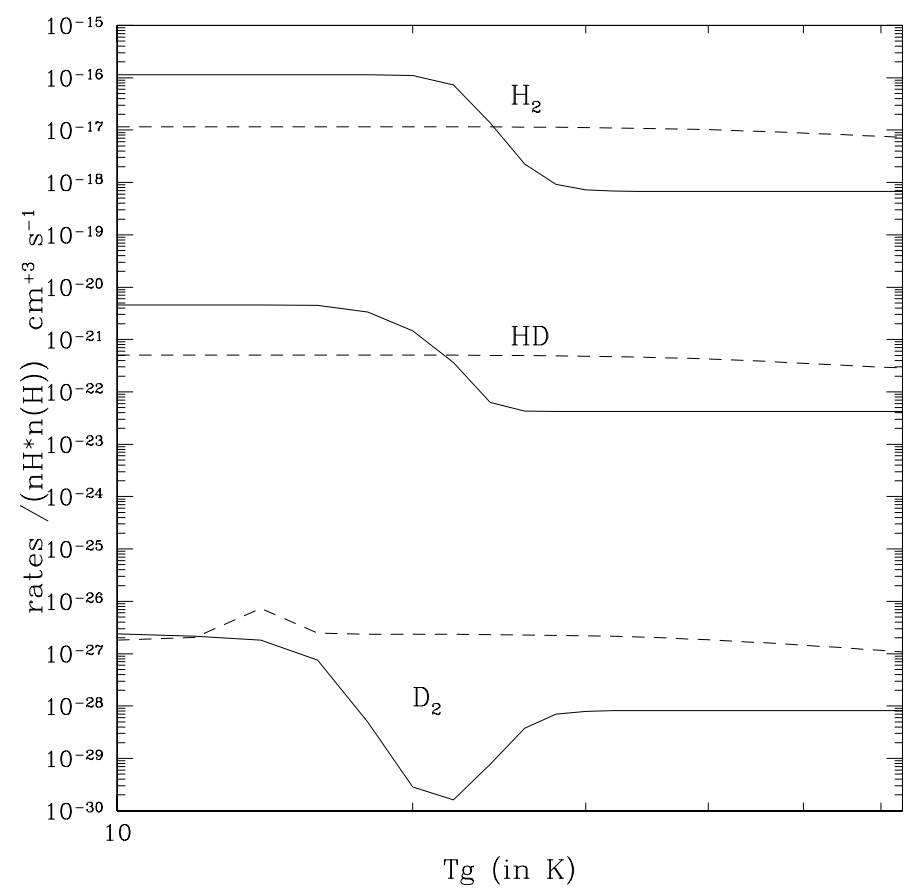

Fig. 15. Formation rate of $\mathrm{H}_{2}, \mathrm{HD}$, and $\mathrm{D}_{2}$ on small grains and PAHs (solid lines) and big grains (dashed lines) as a function of grain temperatures.

(25 ̊), the fluctuations are even greater (from few $\mathrm{K}$ to $50 \mathrm{~K}$ ), but the grain spends $95 \%$ of its life at temperatures below $20 \mathrm{~K}$. In this study we did not consider the temperature fluctuations of small grains. The limiting factor in the formation of molecules on very small grains is accretion. In environments with a density of $100 \mathrm{~cm}^{-3}$, a small grain of $10 \AA(30 \AA)$ will receive an $\mathrm{H}$ atom from the gas phase every $7 \times 10^{6}\left(7 \times 10^{5}\right)$ seconds and a D atom every $3 \times 10^{11}\left(3 \times 10^{10}\right) \mathrm{s}$. Once the atom arrives on the grain, it can evaporate (if $T_{\text {dust }} \geq 20 \mathrm{~K}$ for graphitic 
surface, and for very high temperatures for amorphous carbon surface, see Fig. 2), or become chemisorbed in a few hundred seconds (on graphitic surfaces) and a few tens of seconds (on amorphous carbon surfaces). This time can be estimated by $\frac{1}{\alpha_{\mathrm{pc}}}$, and the number of physisorbed sites that the atom will visit can be estimated by the ratio $\frac{\alpha_{\mathrm{pp}}}{\alpha_{\mathrm{pc}}}$. Therefore, in most cases an atom coming onto a grain will become chemisorbed in an empty or in a filled chemisorbed site. In the latter case, a molecule will be formed. If the grain is at temperatures higher than $20 \mathrm{~K}$, then the atom will evaporate and no molecule will be formed. Therefore, the temperature fluctuations of dust grains should reduce the efficiency of the formation of the molecules by a maximum of $10 \%$ for grains lower than $100 \AA$ (which spend $90 \%$ of their life at temperatures below $20 \mathrm{~K}$ ). A recent study by Cuppen et al. (2006) shows that, when considering grains that possess only physisorbed sites, the efficiency depends both on the modal temperature (the most frequent temperature of the grain) and its fluctuations. In this case, these fluctuations shut down the formation of $\mathrm{H}_{2}$ on grains smaller than $100 \AA$ when rough surfaces are considered. In our case, because we consider chemisorbed atoms, the formation of $\mathrm{H}_{2}$ will just slightly decrease by a maximum $10 \%$ (for graphitic surfaces) or will not decrease at all (for amorphous carbon surface).

Another important process that we did not take into account in this study is the so-called "hot-atom-mechanism". An atom that becomes physisorbed on a dust grain is not directly in thermal equilibrium with the grain. In most cases, the atom comes from the gas phase with a higher energy, and once on the grain surface, it bounces against potential walls and slowly loses its energy. Such a process has been described by Buch \& Zhang (1991), and shows how many sites an atom can scout before being in thermal equilibrium with the grain. In our study, the efficiencies of the formation of the different molecules is lower at low grain temperatures. Indeed, at grain temperatures less than $10 \mathrm{~K}$, atoms visit grain surfaces through tunnelling and when they meet to form molecules, a fraction of the newly formed molecules stay on the grain. Therefore, the reason for a low formation efficiency is that dust grains are saturated with molecules. In this study, the hot-atom-mechanism will not increase the efficiency of the formation of molecules at low grain temperature.

\section{Conclusions}

We developed a rate equation model for the formation of $\mathrm{H}_{2}$ and its deuterated forms on carbonaceous surfaces. This model takes the structure of carbonaceous surfaces into account in order to describe the formation mechanism of the different molecules. Small carbonaceous grains $(\leq 100 \AA)$, also called PAHs, possess surfaces that are similar to graphite, while big grains have surfaces similar to amorphous carbon. One or the other type of grain, and therefore of the surface, will have a big impact on the chemistry and the deuteration of $\mathrm{H}_{2}$.

Small grains present surface characteristics similar to graphitic surfaces, which show a high barrier against chemisorption. Big grains, on the other hand, have surfaces similar to amorphous carbon that present no barrier against chemisorption. Because of their mass differences, $\mathrm{H}$ and $\mathrm{D}$ atoms will overcome high barriers against chemisorption with different efficiencies. H atoms can easily tunnel through the barrier to populate the chemisorbed sites. D atoms, which have higher mass, do not tunnel efficiently and therefore mostly populate physisorbed sites. This segregation leaves the D atoms free to travel and associate on physisorbed sites, while the $\mathrm{H}$ atoms are trapped in chemisorbed sites. In this sense, small grains (graphitic surface) favour deuteration.

The rate equation method is applicable only when there is at least one species on the grain. For molecular hydrogen, this method is always valid since an $\mathrm{H}_{2}$ molecule is formed through the association of a physisorbed and a chemisorbed $\mathrm{H}$ atoms. Because half of the chemisorbed sites are filled with hydrogen, there is always more than one $\mathrm{H}$ on the surface, so rate equations are always valid.

In the case of deuterium, because of the low $\mathrm{D} / \mathrm{H}$ ratio in the ISM, it is common that a grain possesses less than $1 \mathrm{D}$ atom on its surface. To understand the formation of $\mathrm{HD}$ and $\mathrm{D}_{2}$ in this case, we developed a Monte Carlo simulation. Our results show that HD formation efficiency increases with smaller grain sizes, while $\mathrm{D}_{2}$ decreases. Indeed, with decreasing grain sizes, the number of physisorbed D decreases, and therefore a D atom on a grain, will easily get trapped in a chemisorbed site and form $\mathrm{HD}$, instead of finding another physisorbed $\mathrm{D}$ and form $\mathrm{D}_{2}$. We propose an approximation to describe the formation of HD and $\mathrm{D}_{2}$ as a function of grain sizes.

We calculated the formation rate of $\mathrm{H}_{2}$ and its deuterated forms when the grain sizes follow the Weintgartner \& Draine (2001) distribution. We differentiated the contribution of small ( $\leq 100 \AA$; Gr Grains) and big grains (AC grains) in the formation of the different species. Our results show that $\mathrm{H}_{2}$ and HD are formed at low grain temperature $(\leq 25 \mathrm{~K})$ mostly on small grains ( $\mathrm{Gr}$ grains), and on big grains at higher grain temperatures (AC grains). The formation of $\mathrm{D}_{2}$, on the other hand, can be dominated by the contribution of big grains for high densities and of small grains for low densities.

This paper sheds some light on the chemistry of species on realistic dust grains, which possess both physisorbed and chemisorbed sites. On big grains, certain molecules form through the association of 2 physisorbed atoms. On small grains, the physisorbed atoms are much less abundant and become chemisorbed before finding another physisorbed atom on the surface. Therefore, small grains will favour the formation of molecules through the association of physisorbed and chemisorbed atoms.

Acknowledgements. We would like to thank the referee for his constructive comments that helped significantly in improving this manuscript.

\section{References}

Allers, K. N., Jaffe, D. T., Lacy, J. H., Draine, B. T., \& Richter, M. J. 2005, ApJ, 630,368

Aronowitz, S., \& Chang, S. 1980, ApJ, 242, 149

Bachellerie, D., Sizun, M., Teillet-Billy, D., Rougeau, N., \& Sidis, V. 2007, Chem. Phys. Let., 448, 223

Barthel, P., \& van Bemmel, I. 2003, New Astron. Rev., 47, 199

Bergin, E. A., Hartmann, L. W., Raymond, J. C., \& Ballesteros-Paredes, J. 2004, ApJ, 612, 921

Boulanger, F., Abergel, A., Bernard, J.-P., et al. 1996, A\&A, 312, 256

Buch, V., \& Zhang, Q. 1991, ApJ, 379, 647

Cazaux, S., \& Tielens, A. G. G. M. 2002, ApJ, 575, L29

Cazaux, S., \& Tielens, A. G. G. M. 2004, ApJ, 604, 222

Chang, Q., Cuppen, H. M., \& Herbst, E. 2005, A\&A, 434, 599

Chang, Q., Cuppen, H. M., \& Herbst, E. 2007, A\&A, 469, 973

Cuppen, H. M., \& Herbst, E. 2005, MNRAS, 361, 565

Cuppen, H. M., Morata, O., \& Herbst, E. 2006, MNRAS, 367, 1757

Duley, W. W., \& Williams, D. A. 1984, Nature, 311, 685

Dulieu, F., Amiaud, L., Baouche, S., et al. 2005, Chem. Phys. Lett., 404, 187

Dwek, E., Arendt, R. G., Fixsen, D. J., et al. 1997, ApJ, 475, 565

Fall, S. M., Pei, Y. C., \& McMahon, R. G. 1989, ApJ, 341, L5

Fromherz, T., Mendoza, C., \& Ruette, F. 1993, MNRAS, 263, 851

Ghio, E., Mattera, L., Salvo, C., Tommasini, F., \& Valbusa, U. 1980, J. Chem. Phys., 73, 556 
Gould, R. J., \& Salpeter, E. E. 1963, ApJ, 138, 393

Green, N. J. B., Toniazzo, T., Pilling, M. J., et al. 2001, A\&A, 375, 1111

Gry, C., Boulanger, F., Nehmé, C., et al. 2002, A\&A, 391, 675

Güttler, A., Zecho, T., \& Kuppers, J. 2004, Chem. Phys. Lett., 395, 171

Habart, E., Boulanger, F., Verstraete, L., Walmsley, C. M., \& Pineau des Forêts,

G. 2004, A\&A, 414, 531

Hornekær, L., Baurichter, A., Petrunin, V. V., Field, D., \& Luntz, A. C. 2003, Science, 302, 1943

Hornekær, L., Rauls, E., Xu, W., et al. 2006, Phys. Rev. Lett. 97, 186102

Hollenbach, D. J., \& Tielens, A. G. G. M. 1999, Rev. Mod. Phys., 71, 173

Hollenbach, D. J., Werner, M. W., \& Salpeter, E. E. 1971, ApJ, 163, 165

Jeloaica, L., \& Sidis, V. 1999, Chem. Phys. Lett., 300, 157

Jura, M. 1974, ApJ, 191, 375

Jura, M. 1975, ApJ, 197, 575

Katz, N., Furman, I., Biham, O., Pirronello, V., \& Vidali, G. 1999, ApJ, 522, 305

Klose, S. 1992, A\&A, 260, 321

Lacour, S., André, M. K., Sonnentrucker, P., et al. 2005, A\&A, 430, 967

Ledoux, C., Petitjean, P., \& Srianand, R. 2003, MNRAS, 346, 209

Lipshtat, A., Biham, O., \& Herbst, E. 2004, MNRAS, 348, 1055

Mennella, V., Brucato, J. R., Colangeli, L., \& Palumbo, P. 2002, ApJ, 569, 531

Morisset, S., Aguillon, F., Sizun, M., \& Sidis, V. 2004, J. Chem. Phys., 108, 8571
Morisset, S., Aguillon, F., Sizun, M., \& Sidis, V. 2005, J. Chem. Phys., 122, 194702

Parneix, P., \& Brechignac, P. 1998, A\&A, 334, 363

Pirronello, V., Biham, O., Liu, C., Shen, L., \& Vidali, G. 1997a, ApJ, 483, L131

Pirronello, V., Liu, C., Shen, L., \& Vidali, G. 1997b, ApJ, 475, L69

Pirronello, V., Liu, C., Roser, J. E., \& Vidali, G. 1999, A\&A, 344, 681

Rawlings, M. G., Juvela, M., Mattila, K., Lehtinen, K., \& Lemke, D. 2005, MNRAS, 356, 810

Rigopoulou, D., Kunze, D., Lutz, D., Genzel, R., \& Moorwood, A. F. M. 2002, A\&A, 389, 374

Rougeau, N., Teillet-Billy, D., \& Sidis, V. 2006, Chem. Phys. Lett., 431, 135

Sha, X., \& Jackson, B. 2002, Surface Science, 496, 318

Sha, X., \& Jackson B. 2004, J. Am. Chem. Soc., 126(40), 13095

Tegmark, M., Silk, J., Rees, M. J., Blanchard, A., Abel, T., \& Palla, F. 1997, ApJ, 474,1

Tielens, A. G. G. M., \& Hollenbach, D. 1985a, ApJ, 291, 747

Tielens, A. G. G. M., \& Hollenbach, D. 1985b, ApJ, 291, 722

Weingartner, J. C., \& Draine, B. T. 2001, ApJ, 548, 296

Zecho, T., Guttler, A., Sha, X., Jackson, B., \& Kuppers, J. 2002, J. Chem. Phys., 117,8486 